NASA/TP-2003-212341

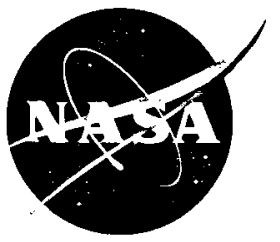

\title{
Magnetic Flux Compression Experiments Using Plasma Armatures
}

M.W. Turner and C.W. Hawk

Propulsion Research Center, The University of Alabama in Huntsville, Huntsville, Alabama

R.J. Litchford

Marshall Space Flight Center, Marshall Space Flight Center, Alabama

National Aeronautics and

Space Administration

Marshall Space Flight Center • MSFC, Alabama 35812 


\section{Acknowledgments}

This work was sponsored by the Advanced Propulsion Research Project Office, Advanced Space Transportation Program, NASA George C. Marshall Space Flight Center. M.W. Turner also acknowledges the financial support of the NASA Graduate Student Researcher Program. The NASA Principal Investigator was Ron J. Litchford.

\section{TRADEMARKS}

Trade names and trademarks are used in this report for identification only. This usage does not constitute an official endorsement, either expressed or implied, by the National Aeronautics and Space Administration.

Available from:

NASA Center for AeroSpace Information

7121 Standard Drive

Hanover, MD 21076-1320

(301) 621-0390
National Technical Information Service 5285 Port Royal Road Springfield, VA 22161

(703) $487-+650$ 


\section{TABLE OF CONTENTS}

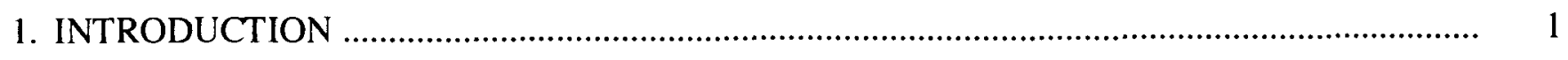

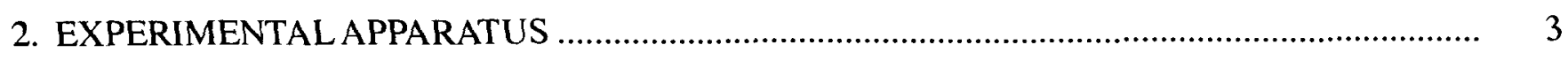

2.1 High-Voltage Capacitor Discharge Bank ................................................................................. 3

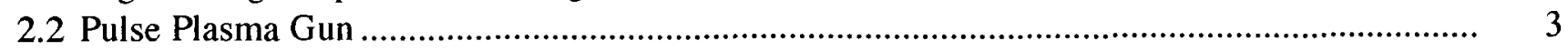

2.3 Optical Probes .................................................................................................................... 4

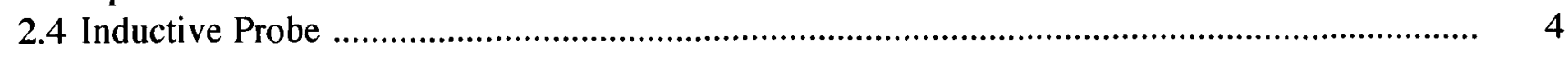

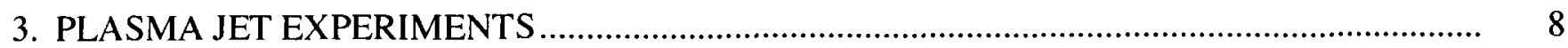

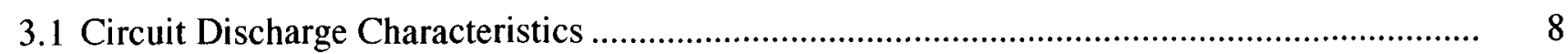

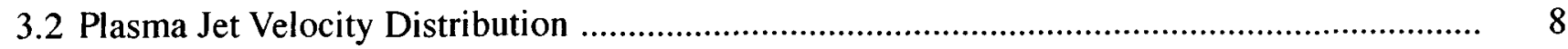

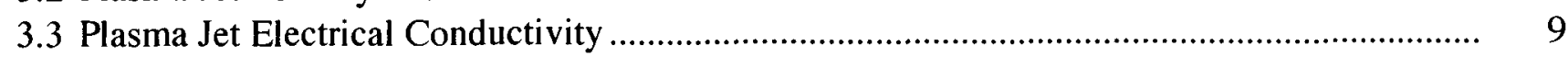

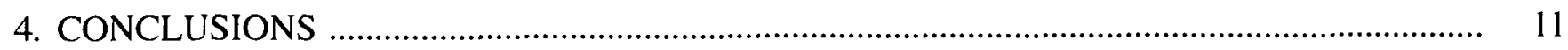

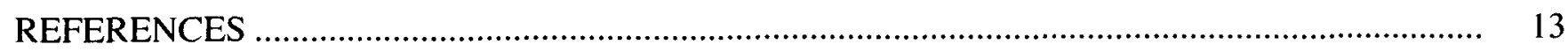




\section{LIST OF FIGURES}

1. Simple radial-mode configuration for basic experimental study of magnetic flux compression processes using a pulse plasma gun source

2. Configuration for plasma jet source characterization experiments

3. Schematic of high-voltage capacitor discharge circuit. The major component specifications are $30-\mathrm{kV} / 33-\mathrm{mA}$ dc power supply; $60-\mathrm{kV} / 2$ - to $8-\mu \mathrm{F}$ capacitor bank; 40-kV/125-A relays; $30-\mathrm{kV}$ power resistors $\left(R_{c}=100 \mathrm{k} \Omega, R_{d}=10 \mathrm{k} \Omega, R_{b}=10 \mathrm{M} \Omega\right)$; and 30-kV-spark gap switch

4. Assembly drawing of the $30^{\circ}$ conical pulse plasma gun and photographs of the assembled units

5. Illustration of inductive probe principle of operation. The plasma jet displaces the field lines of the excitation coil and induces an electromotive force in the search coil. The degree of field displacement can be correlated with plasma jet electrical conductivity

6. Diagram of parameters relevant to the mathematical analysis of probe operation

7. Detailed design drawing of probe

8. Measured coil current and field intensity waveforms

9. Illustration of standard and push-pull search coil configurations. The critical damping resistance is $R_{d}=1 \mathrm{k} \Omega-\mathrm{m}$.

10. Schematic of experimental apparatus used for probe calibration. A light-gas gun was used to fire a $10-\mathrm{cm}$-diameter aluminum slug through the probe where velocity was inferred from the deflection of a laser beam

11. Measured response function for standard search coil configuration

12. Gaussian fit of response function for standard search coil configuration

13. Measured discharge current waveform for the pulse plasma gun circuit at $27 \mathrm{kV}$

14. Ensemble-averaged optical probe waveforms at 25 - and 27 -inHg vacuum. Probes are located at $0,1,2,3,4$, and $5 \mathrm{~cm}$ from gun exit 


\section{LIST OF FIGURES (Continued)}

15. Plasma jet axial velocity distribution at $25-$ and 27 -inHg vacuum ..................................... 28

16. Measured probe response at 27 -inHg vacuum and a discharge voltage of $27 \mathrm{kV} \ldots \ldots \ldots \ldots \ldots \ldots . . .29$

\section{LIST OF TABLES}

1. Summary of inductive probe measurement 


\title{
LIST OF ACRONYMS AND SYMBOLS
}

\author{
emf electromotive force \\ $\mathrm{Hg} \quad$ mercury \\ MHD magnetohydrodynamic \\ MSFC Marshall Space Flight Center \\ UAH The University of Alabama in Huntsville
}




\section{NOMENCLATURE}

\begin{tabular}{|c|c|}
\hline$B$ & magnetic flux density \\
\hline$C$ & capacitance \\
\hline $\mathrm{D}$ & diameter \\
\hline$f$ & frequency \\
\hline$f(\xi)$ & distribution function \\
\hline$g(s)$ & measured signal \\
\hline$H$ & magnetic field \\
\hline$H_{z}$ & longitudinal magnetic field \\
\hline$I$ & field coil current \\
\hline$I_{c}$ & calibrated field coil current \\
\hline$K(s, \xi)$ & kernel \\
\hline $\mathrm{L}$ & length \\
\hline$L$ & inductance \\
\hline$L_{c}$ & coil length \\
\hline$L_{p}$ & plasma inductance \\
\hline$l$ & length of the conductive region behind the shock \\
\hline$m$ & mass \\
\hline$N$ & number of coil turns \\
\hline$n$ & number of capacitors \\
\hline$R$ & resistance \\
\hline$R_{b}$ & bleed resistance \\
\hline$R_{c}$ & charging resistance \\
\hline$R_{d}$ & dump resistance \\
\hline$R_{m}$ & magnetic Reynolds number \\
\hline$R_{p}$ & plasma resistance \\
\hline$s$ & distance from the search coil to the shock \\
\hline$t$ & time \\
\hline$U$ & velocity of the shock \\
\hline
\end{tabular}




\section{NOMENCLATURE (Continued)}

$u$

$u_{c}$

$V$

$V_{c}$

$V_{c p}$

$V_{p}$

$V(s)$

$W$

$x$

$\Delta$

$\mu$

$\mu_{0}$

$\mu_{r}$

$\xi=s-x$

$\rho$

$\rho_{c}$

$\sigma$

$\sigma^{*}$

$\sigma_{0}$

$\sigma_{c}$

$\Phi$

$\Phi_{c}$

$\Phi(s)$

$\psi_{1}$

$\psi_{2}$

particle velocity behind the shock

velocity of the calibration slug

voltage

calibration response function or kernel

peak value of calibration slug response

peak value of the calculated voltage curve

output signal of the search coil

energy

distance from the search coil to an arbitrary point behind the shock

differential change

magnetic permeability of material under consideration

magnetic permeability of free space

relative magnetic permeability with respect to free space

distance from an arbitrary location $x$ to the shock

resistivity

calibrated resistivity of slug

electrical conductivity

maximum conductivity

characteristic plasma electrical conductivity

calibrated slug conductivity

area of measured voltage pulse curve

area of calibration response function for slug pulse

integrated induced voltage signal

function dependent on the conductivity distribution

function dependent on the conductivity distribution 
TECHNICAL PUBLICATION

\section{MAGNETIC FLUX COMPRESSION EXPERIMENTS USING PLASMA ARMATURES}

\section{INTRODUCTION}

Practical deep space mission scenarios require extremely high energy density vehicle concepts, and magnetic flux compression reactors appear to offer one plausible means of meeting the rigorous propulsion and power requirements. Litchford et al., for instance, discuss several pulsed magnetic flux compression reactor configurations of potential interest. ${ }^{1}$

In these devices, the expanding diamagnetic plasma cloud produced by a detonation compresses the initial magnetic flux within a semienclosed reactor structure until the expansion is ultimately reversed and expelled by increasing magnetic pressure. Reactors of this type can accomplish two important functions: (1) Collimation and reflection of the hot diamagnetic plasma for direct thrust production with minimal ablative effects; and (2) electric power generation by direct energy conversion. Preliminary system-level assessments indicate that such devices could yield the specific power and spacecraft acceleration levels deemed necessary for practical exploration and development of the solar system.

Of crucial importance to the complex underlying magnetohydrodynamic (MHD) processes in field compression reactors is the magnetic Reynolds number $\left(R_{m}\right)$, the value of which depends upon the product of plasma electrical conductivity and velocity. Indeed, flux diffusion losses into the plasma will be severe unless $R_{m} \gg 1$. As such, a thorough understanding of MHD phenomena at high magnetic Reynolds numbers is essential to the reliable design and operation of flux compression reactors.

Of equal importance is the potential development of Rayleigh-Taylor or interchange instability as a heavy fluid (i.e., plasma) is decelerated by a light fluid (i.e., magnetic field) ${ }^{2-5}$ In this type of instability, the fluids tend to interchange positions into a lower energy state via classic bubble-and-spike formation and can result in the ejection of high-speed jets from the main plasma cloud which may impact the reactor wall with disastrous consequences. It is therefore essential to have a reliable working knowledge of the origin and mechanisms of this class of instability, which can assume various forms depending upon the magnitude of the ion Larmor radius.

When the Larmor radius is small compared to density gradients and wavelengths, the RayleighTaylor growth rates for the MHD fluids are the same as for ordinary fluids having greatly disparate densities. This was first clearly observed in the classic laboratory plasma gun experiment of Dickinson et al. ${ }^{6}$ On the other hand, when the ion Larmor radius takes on values comparable to the density gradient length, the MHD instability regime is predicted to stabilize. Ironically, it has been discovered that as the ion Larmor radius becomes large compared to the characteristic dimensions of the plasma (i.e., when the ions become 
effectively unmagnetized while the electrons remain effectively magnetized), an entirely new form of interchange instability emerges having a growth rate larger than the original MHD instability. ${ }^{7}$

As a means of acquiring a deeper level of understanding with respect to these phenomena, the authors have embarked on a series of simplified flux compression laboratory experiments designed to shed insight into the physical processes of critical importance. Specifically, we intend to explore a plasma gun configuration similar to that introduced by Dickinson et al. in which the ejected plasma impacts a solid metal barrier and forms a radially expanding plasma armature, which in turn interacts with an applied axial magnetic field. ${ }^{6}$ Following a previous suggestion of Litchford et al., ${ }^{1}$ it is also deemed desirable to explore high-temperature superconducting materials for use as a stator compression surface. The basic experimental configuration of interest is shown in figure 1.

As a prelude to this intensive basic scientific study, exploratory experiments have been carried out as part of an attempt to quantify the magnetic Reynolds number characteristics of the plasma jet source. In this experimental effort, illustrated schematically in figure 2 , the plasma jet velocity was deduced from time-of-flight measurements using optical probes and the electrical conductivity was measured using a previously developed inductive probing technique. ${ }^{8}$ This Technical Publication reports the design and development of the basic laboratory apparatus and documents the preliminary results from our initial plasma jet source characterization study. 


\section{EXPERIMENTAL APPARATUS}

The basic apparatus for the plasma jet source characterization study is a high-voltage capacitive discharge circuit coupled with an ablative conical cavity pulse plasma gun which fires into an evacuated cylindrical tube. An inductive probe is used to measure electrical conductivity, and fiber optic probes mounted in the tube wall are coupled to fast response detectors for time-of-flight measurement of jet velocity. The essential subsystems are described in detail in sections 2.1 through 2.4.

\subsection{High-Voltage Capacitor Discharge Bank}

A high-voltage capacitive discharge circuit was designed for general-purpose duty as shown schematically in figure 3 . It consists of a bank of $2-\mu \mathrm{F}, 60-\mathrm{kV}$ capacitors which can be combined in parallel to form a group having a total capacitance of $n C$ where $n=1,2,3$, or 4 and $C=2 \mu \mathrm{F}$. The bank was configured with $n=1$ for all tests in this particular series of experiments.

The circuit incorporates a 30-kV, 33-mA high-voltage dc power supply as a charging source for the bank, and various 40-kV-rated relays permit remote operation of the charge-discharge cycle. For example, charging is accomplished by opening the normally closed dump relay, closing the normally open source isolation and ground isolation relays, and supplying power through a charging resistor $\left(R_{c}=100 \mathrm{k} \Omega\right)$ which limits the maximum current draw. Once the bank reaches the desired voltage level, the source isolation and ground isolation relays are opened as a means of isolating the circuit, and the discharge is triggered with a pulse transformer which drives a 30-kV-rated-spark gap switch. If the circuit fails to discharge, the stored energy can be rapidly and safely dissipated in a power resistor $\left(R_{d}=10 \mathrm{k} \Omega\right)$ by simply deactivating the dump relay. A bleed resistor $\left(R_{b}=10 \mathrm{M} \Omega\right)$ is also incorporated into the circuit to provide continuous drainage of energy and to ensure that the bank does not become inadvertently charged.

The high-voltage capacitive discharge circuit is coupled with the pulse plasma gun through a simple coaxial transmission line. A high bandwidth, 10,000:1 voltage divider and a 0.001-mV/A current transducer are also available for monitoring the bank and for accurate measurement of discharge waveforms.

\subsection{Pulse Plasma Gun}

The simple pulse plasma gun developed for the present experiments is geometrically similar to Dickinson's original pulse crater gun. ${ }^{6}$ The basic design is essentially that of a conical cavity pulse plasma thruster in which a pin electrode (i.e., cathode) is situated at the apex of the cone and a ring electrode (i.e., anode) is situated at the base of the cone. The conical insulator is machined from DuPont's Teflon ${ }^{\circledR}$, which serves as an ablative propellant source during high current discharge.

Two plasma guns were designed and constructed with included cavity angles of $30^{\circ}$ and $60^{\circ}$, respectively. The assembly drawing for the $30^{\circ}$ conical plasma gun is shown in figure 4 along with photographs of the assembled units. 


\subsection{Optical Probes}

The pulse plasma gun is mated to an evacuated tube having fiber optic probes embedded at $1 / 2-\mathrm{cm}$ intervals along its length. The design includes a total of 12 probes yielding an active probing length of $6 \mathrm{~cm}$. These fiber optic probes are connected to fast rise time $(1 \mathrm{~ns})$ detectors whose output signals are recorded with high bandwidth digital oscilloscopes. The authors recognize that the true plasma jet leading edge may not be spatially correlated with optical emission; nevertheless, the time of flight of optical emission is considered a reasonable basis for estimating plasma jet velocity.

\subsection{Inductive Probe}

In the current set of experiments, an attempt was made to measure plasma jet electrical conductivity using a weakly intrusive inductive probing technique that was originally developed for shock wave studies. ${ }^{9}$ In previous related work, the authors succeeded in adapting this inductive probing scheme for application to plasma jets emitted from shaped charge explosives, ${ }^{8}$ and it was believed that the technique could also be successfully adapted for the pulse plasma gun source. A brief summary of inductive probe theory, design, calibration, and operation is provided below, and the reader is referred to the original sources for further details.

\subsubsection{Fundamental Principles of Operation}

The inductive probe, illustrated in figure 5, is a simple electromagnetic system consisting of two adjacent coils wound on a nonmagnetic tube. The field coil (i.e., solenoid) is first excited by a dc power supply in order to introduce an axisymmetric magnetic field inside the tube. The resulting field lines are illustrated in figure 5. A small search coil is situated slightly forward of the excitation coil to pick up the electromagnetic disturbance produced by passage of the plasma jet.

As the plasma jet enters the field region, it displaces the magnetic field lines due to its diamagnetic properties. That is, eddy currents are established in the plasma which resist magnetic field penetration. This perturbation, or compression, of the magnetic field lines induces an electromotive force (emf) in the search coil. The magnitude of the emf is representative of the degree of field displacement and, given the jet velocity, can be correlated with the plasma electrical conductivity. Actual recovery of the electrical conductivity distribution from the induced emf signal requires the difficult inversion of a Fredholm integral equation of the first kind, as shown in section 2.4.2 which is devoted to the mathematical theory of probe operation.

In principle, the plasma conductivity can be directly calculated from the coil geometry and the known jet velocity; however, Lin et al. have demonstrated that it is much easier to obtain the probe response function empirically by firing a metallic slug of known conductivity through the device. ${ }^{9}$

\subsubsection{Mathematical Theory of Operation}

Following the mathematical analysis of Lin et al. for the inductive probe, we arrive at a Fredholm integral equation of the first kind for the conductivity $(\sigma)^{9}$ 


$$
\Phi(s)=\frac{U u I}{u_{c}^{2} I_{c} \sigma_{c}} \int_{0}^{l} V_{c}(s-\xi) \sigma_{0}(\xi) d \xi
$$

where $\Phi(s)$ is the integrated induced voltage signal on the search coil,

$$
\Phi(s)=\int_{0}^{s} V(s) d s
$$

and $V(s)$ is the output signal of the search coil. A diagram of the parameters relevant to the mathematical analysis is given in figure 6 . The major parameters are the length of the conductive region behind the shock $(l)$, the distance from the search coil to the shock $(s)$, the distance from the search coil to an arbitrary point behind the shock $(x)$, the distance from an arbitrary location $x$ to the shock $(\xi=s-x)$, the velocity of the shock $(U)$, the particle velocity behind the shock $(u)$, the field coil current during a test $(I)$, the velocity of the calibration slug $\left(u_{c}\right)$, the field coil current during calibration $\left(I_{c}\right)$, the electrical conductivity of the calibration slug $\left(\sigma_{c}\right)$, the calibration slug response function or kernel $\left(V_{c}\right)$, and the unknown plasma electrical conductivity distribution $\left(\sigma_{0}\right)$.

The Fredholm integral equation of the first kind has the general form

$$
g(s)=\int_{a}^{b} K(s, \xi) f(\xi) d \xi
$$

where $g(s)$ is a known function (i.e., the measured signal), $K(s, \xi)$ is the kernel, and $f(\xi)$ is the unknown distribution function. In general, closed-form analytical inversions can be obtained only for special functions, and one must resort to numerical methods.

Numerical deconvolution algorithms for recovering $f(\xi)$ are generally based on a linear vector space representation of equation (3). Turner et al. discuss the numerical inversion issues associated with this inversion, including the severe instabilities commonly encountered with the Fredholm integral equation of the first kind, and they demonstrate the application of a constrained linear inversion technique to this problem.

In many cases, however, interpretation of the experimental data can be facilitated by an approximate treatment of the integral equation. For example, Lin et al. showed that it is possible to express the ratio between the maximum conductivity $\left(\sigma^{*}\right)$ behind the shock wave and the calibration slug conductivity $\left(\sigma_{C}\right)$ as

$$
\frac{\sigma^{*}}{\sigma_{c}}=\frac{u_{c}^{2} I_{c} V_{p}}{U u I V_{c p}} \psi_{1}
$$

and

$$
\frac{\sigma^{*}}{\sigma_{c}}=\frac{u_{c}^{2} I_{c} \Phi}{U u I \Phi_{c}} \psi_{2}
$$


where $V_{c p}$ and $\Phi_{c}$ are the peak and the pulse area of the calibration slug response function, respectively; $V_{p}$ and $\Phi$ are the peak and the pulse area of the calculated voltage curve; and $\psi_{1}$ and $\psi_{2}$ are functions dependent on the conductivity distribution. Various results for different conductivity distributions are tabulated in the literature. ${ }^{9}$

For the special case where the conductivity distribution is a step function and the probe response function is Gaussian, both $\psi_{1}$ and $\psi_{2}$ are unity. When the conductivity distribution deviates from a step function, it turns out that $\psi_{1}$ and $\psi_{2}$ are equal to unity plus a small correction term. This mathematical behavior is extremely useful for the purpose of estimating the characteristic plasma jet conductivity encountered in our experiments.

\subsubsection{Probe Design}

The detailed design of the inductive probe is shown in figure 7 . The basic structure is a nylon coil form which has been machined to accept two coil windings. The coil form has a bore diameter of 1.3 in and a wall thickness of $0.125 \mathrm{in}$. A 900-turn magnet field coil was wound from No. 18 enameled magnet wire. The resulting solenoid has a length of 1.5 in and an outer diameter of $3.8 \mathrm{in}$. The search coil consists of dual 25 -turn windings of No. 28 enameled magnet wire. These windings can be connected in series or in a pushpull configuration as demonstrated by Lin et al. ${ }^{9}$

The excitation field coil was designed to produce a solenoidal magnetic field between 0.5 and $1 \mathrm{~T}$ inside the bore. A $20-\mathrm{kW}$ dc power supply was used to drive the excitation coil at $300 \mathrm{~V}$ (maximum), and the operating time was limited to $1 \mathrm{~s}$ in order to minimize resistive heating.

The field coil was calibrated by measuring the time-varying current when activated by a solenoid switch. The time-varying magnetic field in the bore was also measured using a Hall probe connected to a Gauss meter. The resulting waveforms are shown in figure 8 at maximum applied excitation voltage. We observed a rise time of $20 \mathrm{~ms}$, a peak current of $56 \mathrm{~A}$, and a peak field intensity of $0.8 \mathrm{~T}$. Reproducibility of these waveforms was excellent. The waveforms remained relatively flat around the peak values for $\approx 15 \mathrm{~ms}$ after which they gradually decayed and stabilized to $\approx 63$ percent of their maximum values. Therefore, a 15 -ms target window was identified for probing at maximum field strength.

In the shock tube experiments of Lin et al., electrostatic effects were encountered which were associated with nonuniform charge distributions in the ionized gas. ${ }^{9}$ This effect, while of great physical interest, introduces a finite capacitance between the search coil and the plasma and could lead to spurious signals. This difficulty was overcome by connecting dual-turn windings in a push-pull configuration, as shown in figure 9. The center tap is connected to ground and 1-k $\Omega$ shunt resistors are used to achieve critical damping. In this configuration, the capacitive pickup from the two ends of the coil is canceled while the inductive pickup is unaffected. A similar strategy was implemented in our probe design so that we are able to utilize either a 50-turn standard connection or a dual 25-turn push-pull connection, as needed.

\subsubsection{Probe Calibration}

In order to calibrate the inductive probe, it is necessary to fire a metal slug of known electrical conductivity through the probe. The velocity of the slug must also be measured. To accomplish this 
requirement, a simple compressed light-gas gun was developed using 150 psi helium stored in a small cylinder. The helium was released into the gun breech by a solenoid-actuated valve, which could be triggered electronically, and a 4-in-long, 1-in-diameter aluminum cylinder was propelled down a plastic barrel and through a glass tube holding the probe assembly. The resistivity of the aluminum was $\rho=3 \times 10^{-8} \Omega-\mathrm{m}$. The velocity of the slug was inferred from the deflection of a laser beam. A digital computer-controlled firing sequence was implemented incorporating appropriate timing delays, and the various signal waveforms were captured on a digital oscilloscope. A schematic of the calibration apparatus is shown in figure 10 .

The timing for the calibration experiment was crucial. For example, to hit our target window it was necessary to accurately trigger the excitation field coil $20 \mathrm{~ms}$ before the slug entered the active probe region; otherwise, the probe would not be at maximum field strength at the appropriate moment. This timing problem was summarily resolved after several test shots.

To measure the slug velocity, we directed a laser beam through the glass tube and onto a fast response optical detector. When the slug entered the glass tube, the laser beam was deflected and the detector signal fell. After slug passage, the beam path was cleared and the detector signal returned to its normal value. Therefore, we could determine the time of flight of the slug past the beam and infer the velocity from the known slug length. The captured detector waveforms indicated a time of flight of $\Delta t \approx 5 \mathrm{~ms}$, and we deduced a slug velocity of $2,150 \pm 164 \mathrm{~cm} / \mathrm{s}$.

The measured response function of the standard configuration search coil (50 turns) is shown in figure 11. This waveform, which represents an ensemble average of seven shots, consists of two perturbations. The first is the entrance perturbation associated with initial field displacement as the probe enters the active probe region. The second is the exit perturbation associated with restoration of the original field as the slug leaves the active probe region. When the slug fills the active region completely, there is no signal since the displaced field is quasi-steady. Only the entrance portion of the response function is needed for inversion purposes.

The response function is very nearly Gaussian as can be seen from the fit shown in figure 12. Here, we have transformed to spatial coordinates using the known slug velocity. We observe that the response function reaches a peak value of $\approx 1.3 \mathrm{~V}$ when the leading edge of the slug is $\approx 3.5 \mathrm{~cm}$ past the search coil. The standard deviation of the Gaussian fit is $1.8 \mathrm{~cm}$, indicating that the probe has an effective resolving power of $\approx 4 \mathrm{~cm}$. This is more than sufficient to resolve the leading portion of a plasma jet.

For the push-pull search coil configuration, a response signal is obtained from each segment of the search coil circuit where the output from each segment is referenced to the grounded center tap. Therefore, the entrance perturbation is positive for the push segment and negative for the pull segment. The exit perturbations are also of opposite sign. The response functions are again found to be nearly Gaussian, and the peak signal values are exactly half of that obtained for the standard configuration, as expected. The effective resolving power is also identical to the standard configuration. 


\section{PLASMA JeT EXPERIMENTS}

To characterize the plasma jet source, two series of tests were carried out using the simple experimental setup illustrated in figure 2 . In all of these tests, the vacuum chamber was pumped down to moderately low pressure (i.e., 25- to 27 -inHg vacuum) with natural air as the background gas. The primary objective of the first series of tests was to obtain the plasma jet axial velocity distribution; therefore, they were conducted with the inductive probe removed. The primary objective of the second series of tests was to measure plasma jet electrical conductivity with the inductive probe installed near the exit of the plasma gun. The results are discussed in sections 3.1 through 3.3.

\subsection{Circuit Discharge Characteristics}

The nominal discharge voltage was $27 \mathrm{kV}$ for all of the experiments with $C=2 \mu \mathrm{F}$. This implies the release of $W=1 / 2 C V^{2}=729 \mathrm{~J}$, a large fraction of which is delivered to the plasma jet. The intensity of the resulting discharge was clearly evident from the high levels of erosion experienced by the plasma gun as determined from posttest inspections.

The measured discharge current waveform from a typical shot is shown in figure 13. A peak current of $250 \mathrm{kA}$ was observed with a ring-down time of $\approx 125 \mu \mathrm{s}$. The ringing frequency was $\approx 40 \mathrm{kHz}$. The resulting estimate for effective inductance, assuming a series $L R C$ circuit model, indicates a need to reduce the inductance of the power delivery transmission line. Such modifications will be attempted prior to the initiation of follow-on experimental study.

\subsection{Plasma Jet Velocity Distribution}

With the inductive probe removed from the experiment, a series of shots were made in which the output signals from selected optical probes were recorded with digital oscilloscopes. The selected probe positions were located at $0,1,2,3,4$, and $5 \mathrm{~cm}$ from the plasma gun exit.

Initial tests were carried out at 25 -inHg vacuum to establish a baseline reference. It was quickly determined from the resulting data, however, that the plasma jet velocity was much lower than the targeted value of $10^{4} \mathrm{~m} / \mathrm{s}$. Believing that such poor performance was a direct result of the backpressure being too high, we undertook a second series of shots at 27 -inHg vacuum. The inferred velocities improved dramatically but were still lower than the anticipated target value.

The ensemble-averaged optical probe waveforms for both backpressures are shown in figure 14, and the inferred plasma jet velocity distributions, based on the time difference between rising edges, are provided in figure 15 . At 25 -inHg vacuum, the maximum velocity is $\approx 2 \mathrm{~km} / \mathrm{s}$, and at 27 -inHg vacuum, we observe an increase to $\approx 4.5 \mathrm{~km} / \mathrm{s}$. Although the velocity levels fell short of expectations, a slow axial velocity decay characteristic was achieved, as desired. Clearly, lower backpressures are needed to obtain higher velocities, but lower backpressures may also tend to reduce jet momentum since there will be less ejected mass. 
Unfortunately, attempts to obtain shots at lower backpressures were not successful at this time, apparently due to arcing effects inside the vacuum chamber. Further design modifications will be necessary before it will be possible to obtain reliable velocity data in a lower pressure regime.

\subsection{Plasma Jet Electrical Conductivity}

The final series of tests were carried out with the inductive probe installed in an attempt to measure plasma jet electrical conductivity. In these tests, the search coil was located $\approx 1 \mathrm{~cm}$ from the plasma gun exit. This location was selected based on the criteria that the ring-down process be completed before the plasma jet enters the region of influence of the probe. The previous velocity measurements along with the measured discharge current waveform permitted a preliminary estimate to be made for the appropriate search coil location.

Because the electrical conductivity was anticipated to be relatively high, the inductive probe tests were performed at low excitation coil current. The measured value was nominally $13 \mathrm{~A}$. This was sufficient current to produce $\approx 0.2 \mathrm{~T}$ in the active probing region. It was felt that higher fields would only make the measurement more intrusive without benefiting sensitivity.

To avoid any possible electrostatic effects on the probe measurements, we also elected to utilize the push-pull search coil configuration. During initial testing, however, the search coil signal was subject to an extremely high level of noise, and extraction of a meaningful signal proved impossible. After expending much effort in shielding the signal wires, a waveform was finally acquired in which we had some level of confidence. Unfortunately, attempts at follow-on testing to check for repeatability were not possible due to failure of the excitation coil power supply.

The best measured inductive probe signal was obtained at 27 -inHg vacuum with a discharge charge voltage of $27 \mathrm{kV}$. The resulting waveform (push coil only) is shown in figure 16 following subtraction of the ring-down noise and transformation to the spatial coordinate. The pull-coil waveform is symmetrical with the push-coil waveform about the abscissa and is not shown. The maximum amplitude of probe response was $V_{p}=4.8 \mathrm{~V}$.

The reduced data for this test are summarized in table 1 based on application of both the peak ratio method, equation (4), and the peak integral method, equation (5). It is explicitly assumed that $\psi_{1}$ and $\psi_{2}$ are approximately unity. In general, the integral ratio method is expected to yield a better approximation since $\psi_{2}$ should exhibit less deviation from unity in all cases.

Table 1. Summary of inductive probe measurement.

\begin{tabular}{lccc}
\hline Parameter & Dimension & Peak Ratio & Integral Ratio \\
\hline$U$ & $\mathrm{~km} / \mathrm{s}$ & 4 & 4 \\
$\sigma^{\star} / \sigma_{c}$ & $10^{-4}$ & 9 & 13 \\
$\sigma^{\star} U / \sigma_{c} u_{c}$ & $10^{-2}$ & 17 & 24 \\
$\sigma^{\star}$ & $\mathrm{kS} / \mathrm{m}$ & 30 & 43 \\
$\mu \sigma^{\star} u$ & $\mathrm{~m}^{-1}$ & 150 & 210 \\
\hline
\end{tabular}


The peak electrical conductivity was found to be $\approx 30 \mathrm{kS} / \mathrm{m}$ based on the peak ratio method and $\approx 42 \mathrm{kS} / \mathrm{m}$ based on the integral ratio method. Thus, $\mu \sigma^{*} u \approx 150$ to $210 \mathrm{~m}^{-1}$. This implies that a range $R_{m} \approx 3$ to 5 is achievable with our laboratory scale apparatus. 


\section{CONCLUSIONS}

To summarize, we note that exploratory experiments have been carried out in an attempt to quantify the magnetic Reynolds number characteristics of a simple ablative pulse plasma gun. The jet velocity was inferred from time-of-flight measurements using optical probes, and the electrical conductivity was measured using a previously developed electrodeless inductive probe. Using air at 27 -inHg backpressure, measured velocities were found to approach $4.5 \mathrm{~km} / \mathrm{s}$, and measured conductivities were in the range of 30 to $40 \mathrm{kS} / \mathrm{m}$. This implied the attainment of magnetic Reynolds numbers in the range of 3 to 5 for our small-scale experimental apparatus.

Therefore, it may be concluded that this pulse plasma gun source will provide suitable magnetic Reynolds numbers for supporting an intensive scientific study of magnetic flux compression using a rather simple laboratory configuration. Planned modifications to the power delivery transmission line and vacuum insulation design should permit the attainment of higher jet velocities at lower backpressures with the potential for increasing the magnetic Reynolds number range even further. 


\section{REFERENCES}

1. Litchford, R.J.; Robertson, G.A.; Hawk, C.W.; Turner, M.W.; and Koelfgen, S.: "Magnetic Flux Compression Reactor Concepts for Spacecraft Propulsion and Power," NASA TP-2001-210793, Marshall Space Flight Center, AL, January 2001; AIAA Paper 2000-2669, June 2000.

2. Lord Rayleigh: "Investigation of the Character of the Equilibrium of an Incompressible Heavy Fluid of Variable Density," Scientific Papers, Vol. II, Cambridge, England, 1900.

3. Taylor, G.I.: "The Instability of Liquid Surfaces when Accelerated in a Direction Perpendicular to their Planes," Proc. Roy. Soc. London Series A, Vol. 201, pp. 192-196, 1950.

4. Kruskal, M.; and Schwarzschild, M.: "Some Instabilities of a Completely Ionized Plasma," Proc. Roy. Soc. London Series A, Vol. 223, pp. 348-360, 1954.

5. Chandrasekhar, S.: Hydrodynamic and Hydromagnetic Instabilities, Clarendon Press, Oxford, 1961.

6. Dickinson, H; Bostick, W.H.; DiMarco, J.N.; and Koslov, S.: "Experimental Study of Rayleigh-Taylor Instability in Plasma," Physics of Fluids, Vol. 5, No. 9, pp. 1048-1056, 1962.

7. Ripin, B.H.; McClean, E.A.; Manka, C.K.; Pawley, C.; Stamper, J.A.; Peyser, T.A.; Mostovych, A.N.; Grun, J.; Hassam, A.B.; and Huba, J.: "Large-Larmor-Radius Interchange Instability," Phys. Rev. Letters, Vol. 59, No. 20, pp. 2299-2302, November 1987.

8. Turner, M.W.; Hawk, C.W.; and Litchford, R.J.: "Inductive Measurement of Plasma Jet Electrical Conductivity," NASA TP-200I-210794, Marshall Space Flight Center, AL, January 2001; AIAA Paper 2000-3369, July 2000.

9. Lin, S.-C.; Resler, E.L.; and Kantrowitz, A.: "Electrical Conductivity of Highly lonized Argon Produced by Shock Waves," J. App. Phys., Vol. 26, No. 1, pp. 95-109, January 1955. 


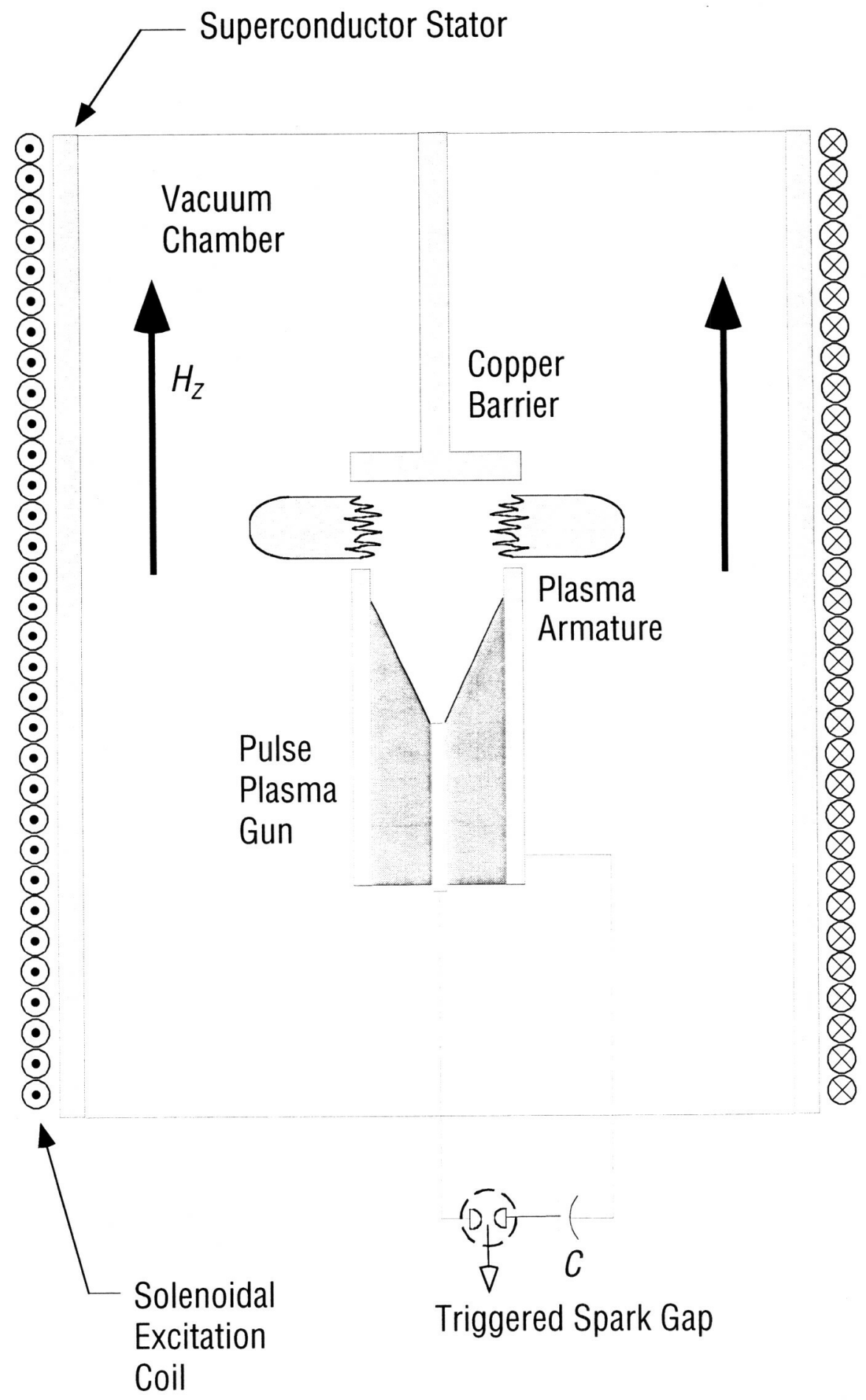

Figure 1. Simple radial-mode configuration for basic experimental study of magnetic flux compression processes using a pulse plasma gun source. 


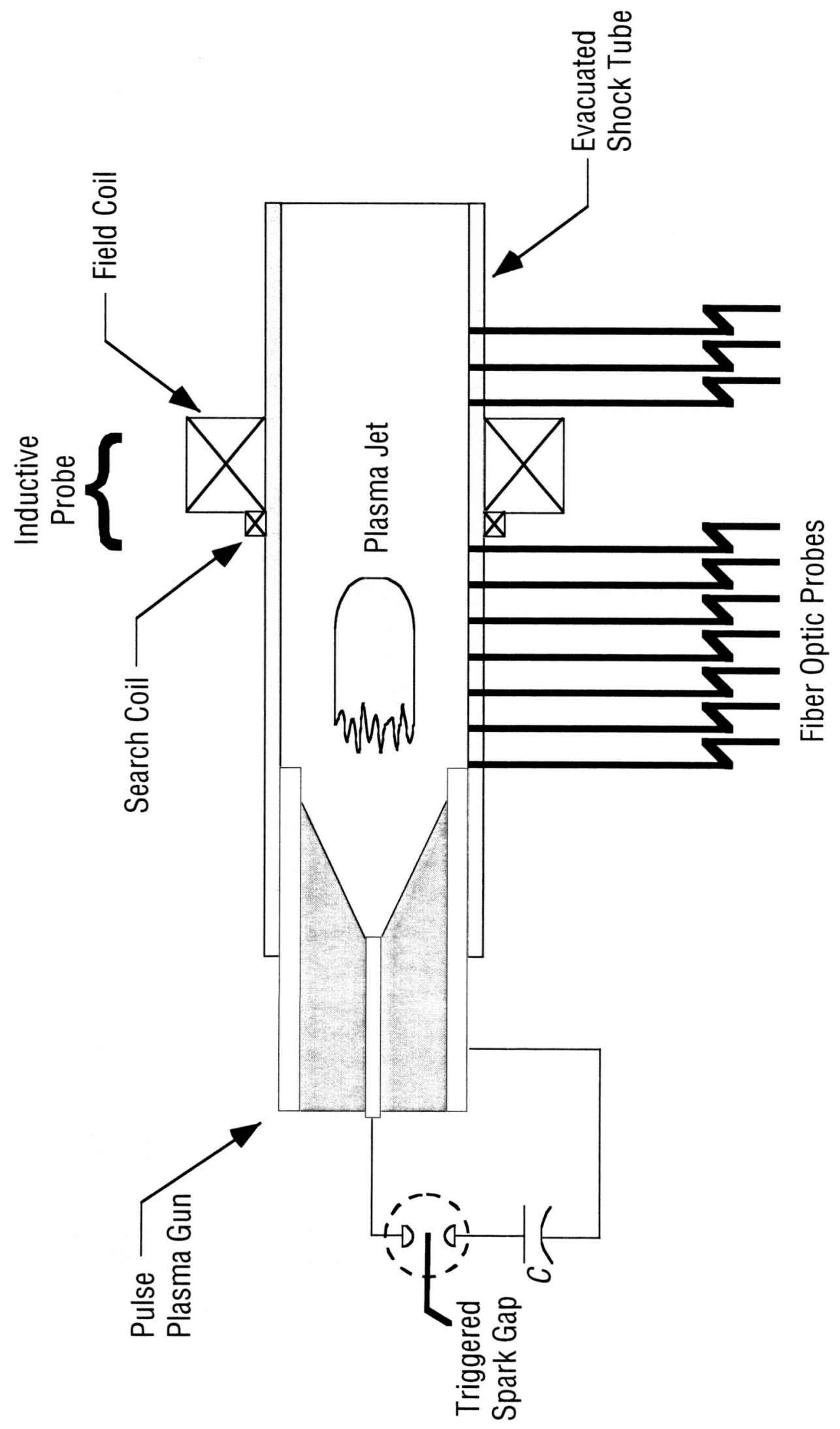

Figure 2. Configuration for plasma jet source characterization experiments. 


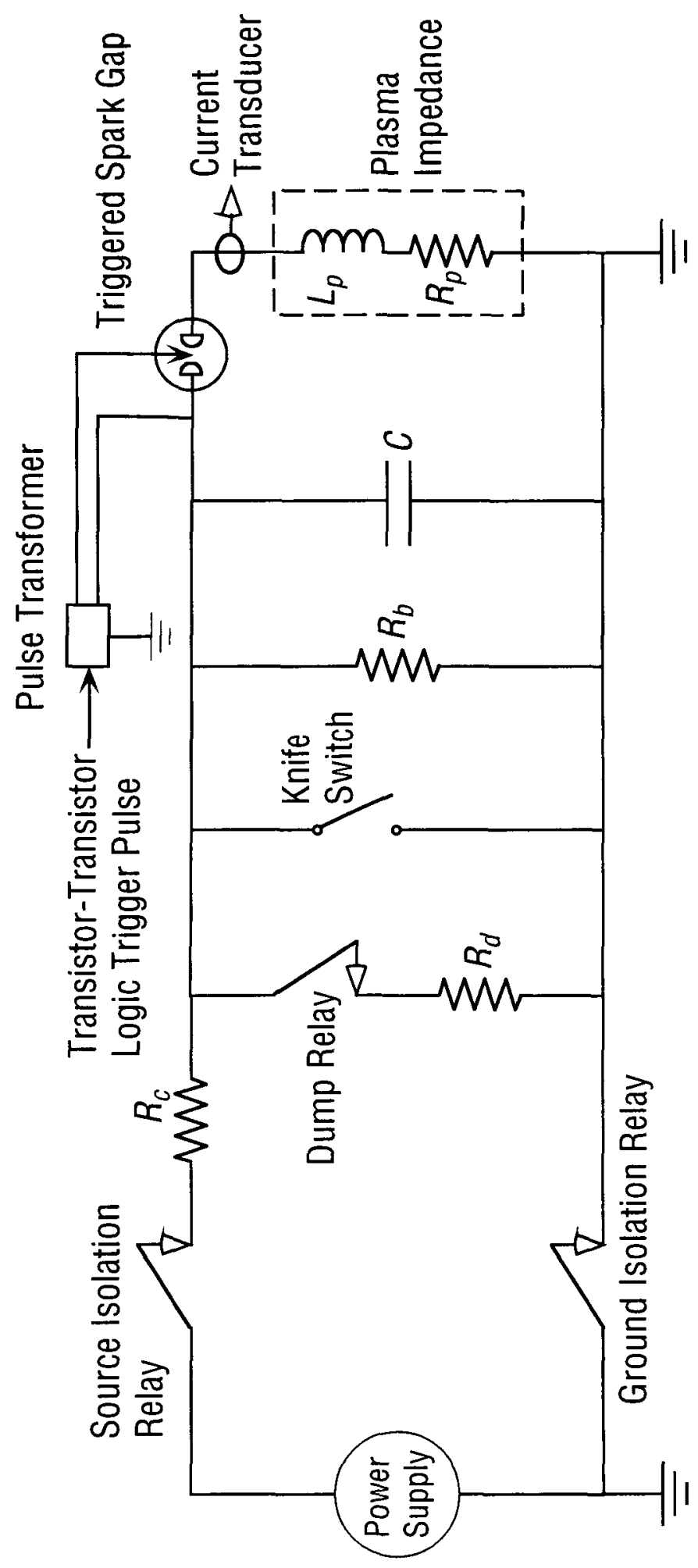

Figure 3. Schematic of high-voltage capacitor discharge circuit. The major component specifications are 30-kV/33-mA dc power supply; $60-\mathrm{kV} / 2$ - to $8-\mu \mathrm{F}$ capacitor bank; $40-\mathrm{kV} / 125$-A relays; $30-\mathrm{kV}$ power resistors $\left(R_{c}=100 \mathrm{k} \Omega, R_{d}=10 \mathrm{k} \Omega, R_{b}=10 \mathrm{M} \Omega\right)$; and 30-kV-spark gap switch. 

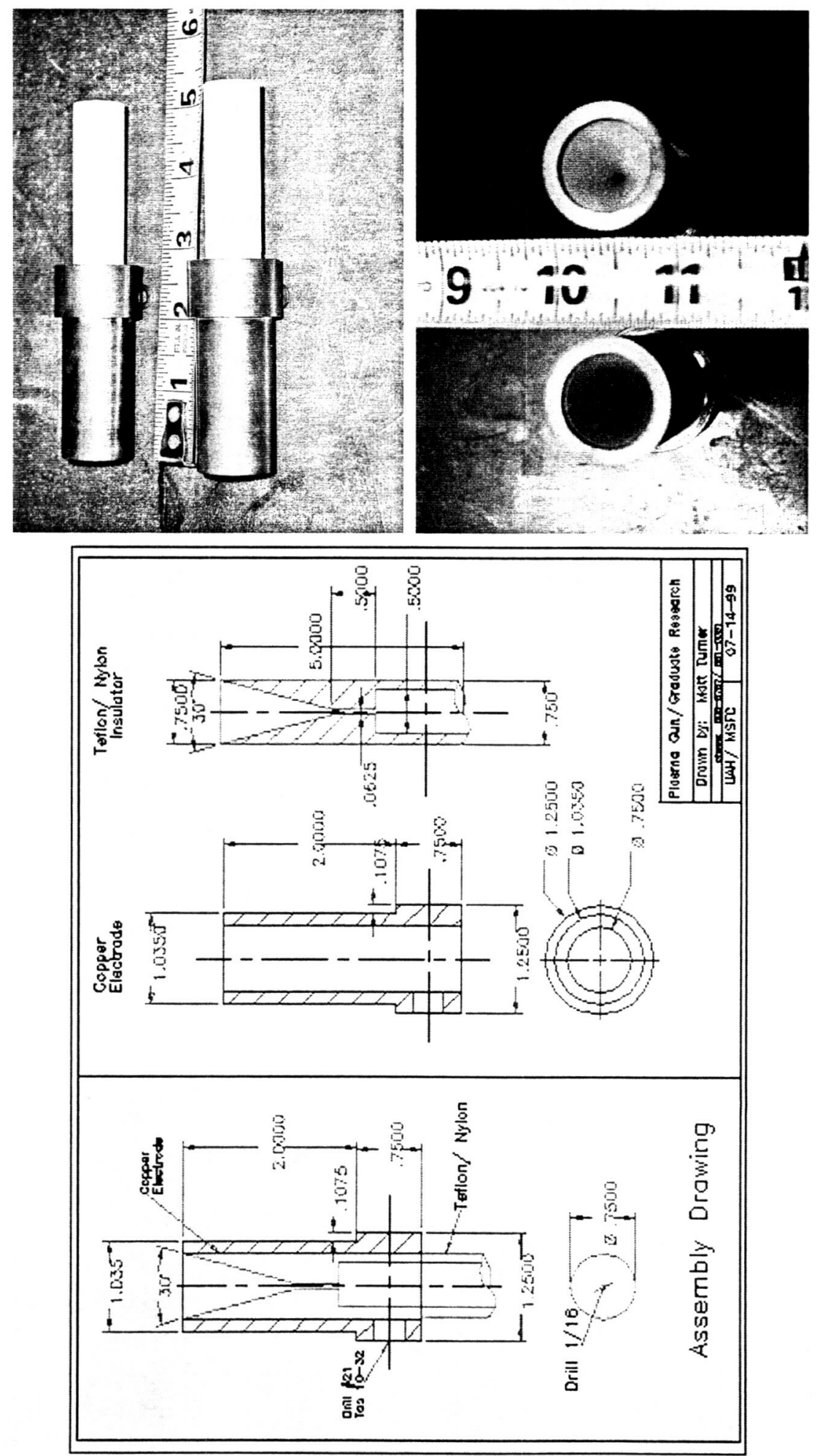

Figure 4. Assembly drawing of the $30^{\circ}$ conical pulse plasma gun and photographs of the assembled units. 


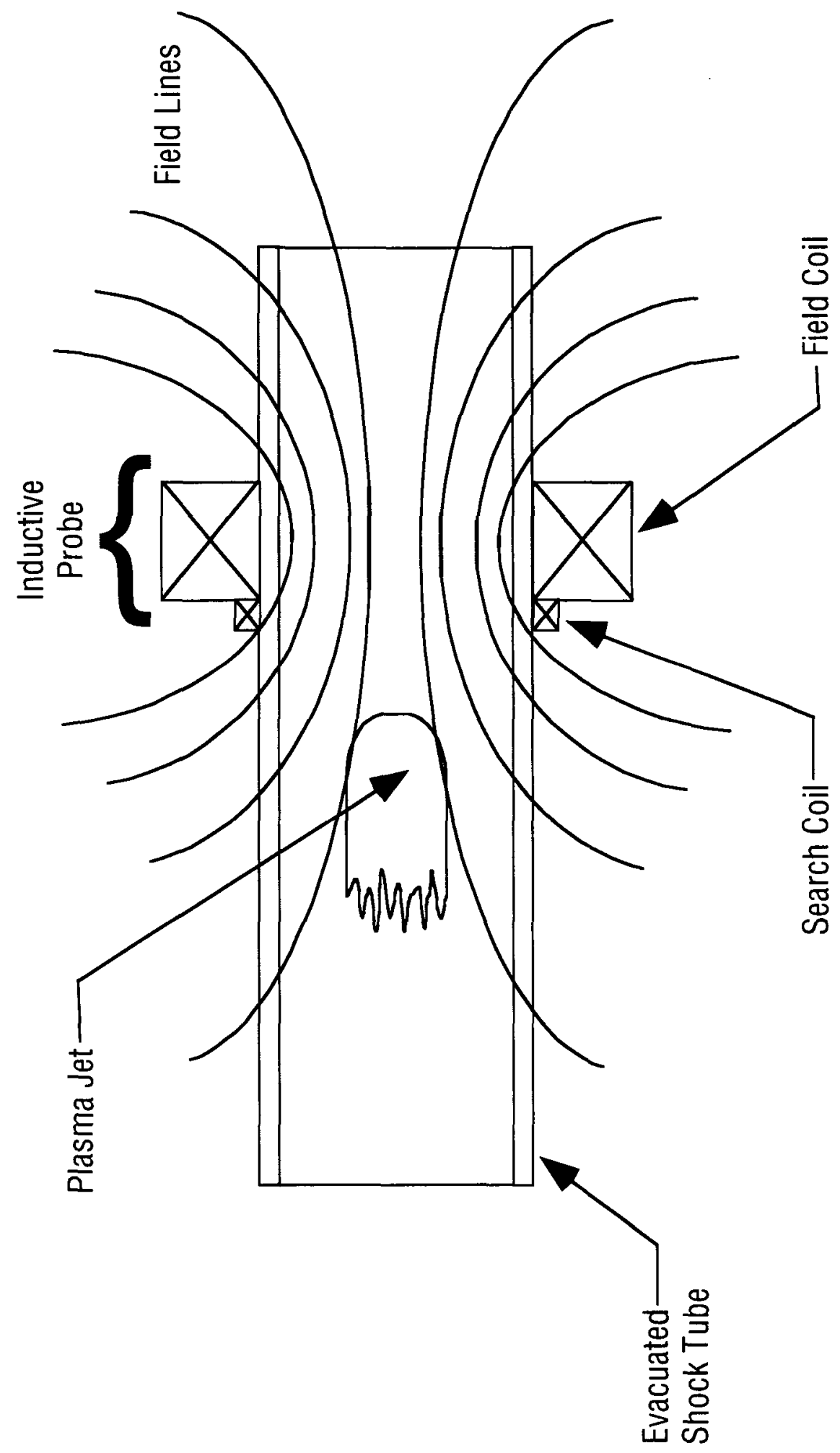

Figure 5. Illustration of inductive probe principle of operation. The plasma jet displaces the field lines of the excitation coil and induces an electromotive force in the search coil. The degree of field displacement can be correlated with plasma jet electrical conductivity. 


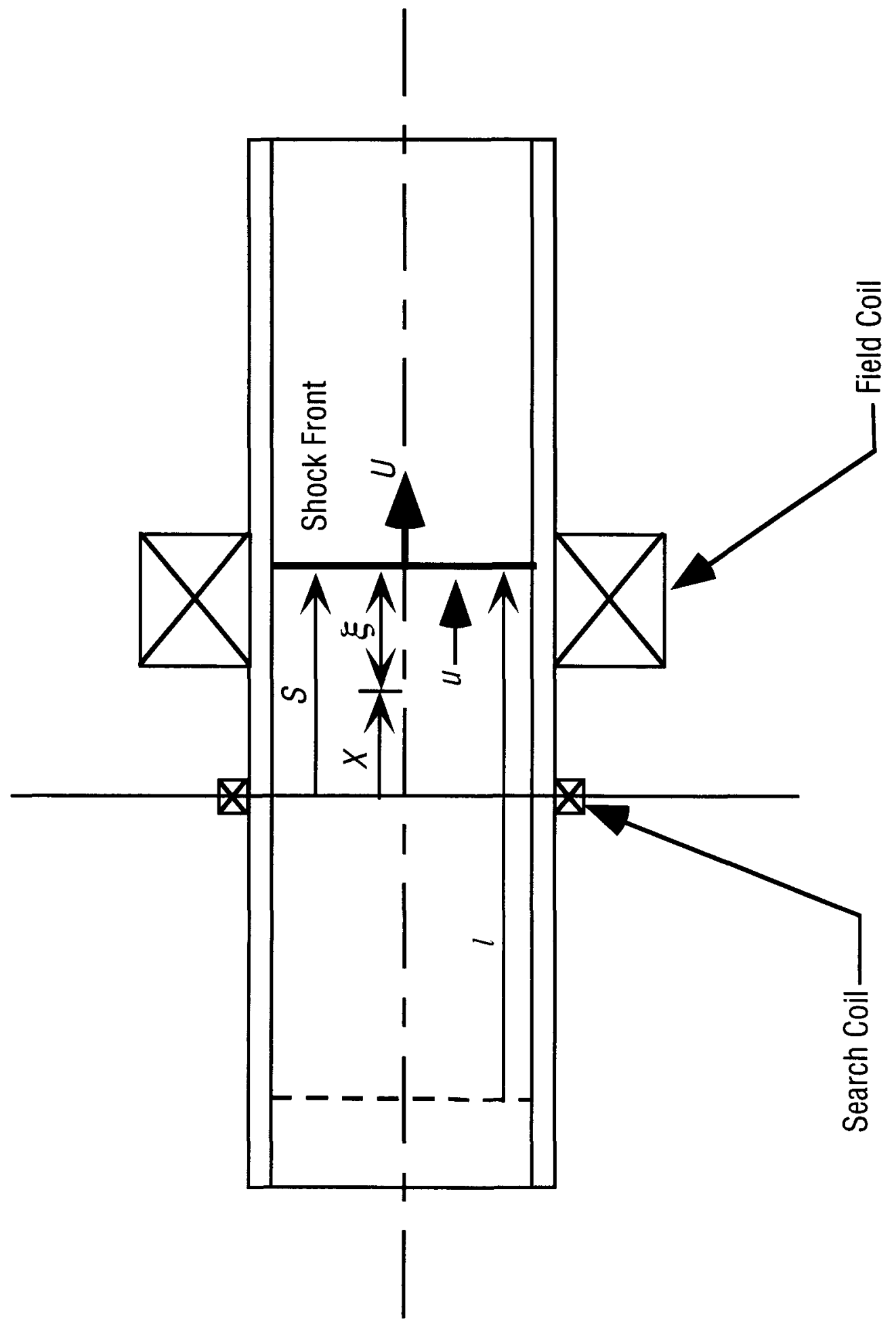

Figure 6. Diagram of parameters relevant to the mathematical analysis of probe operation. 


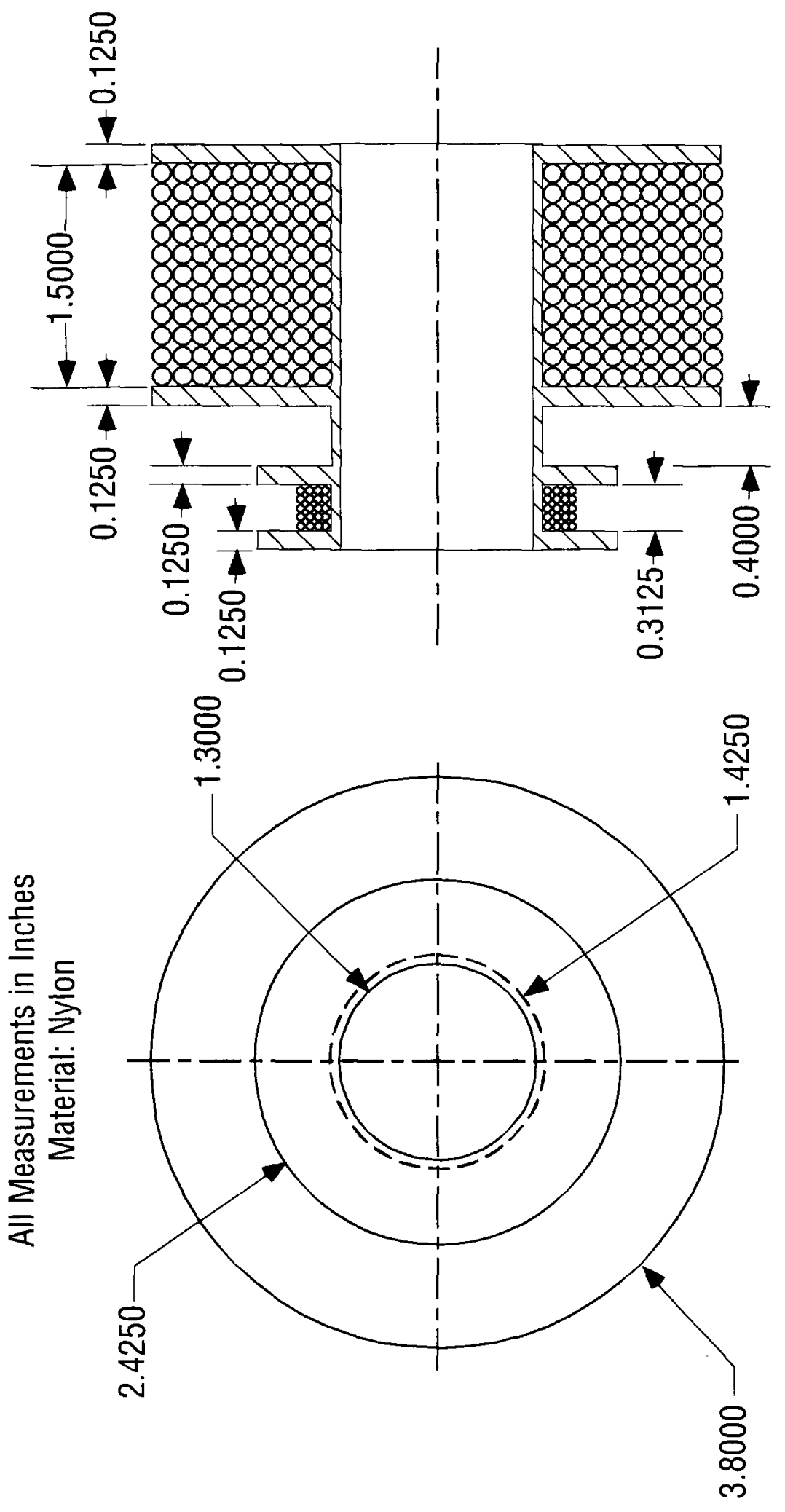

Figure 7. Detailed design drawing of probe. 


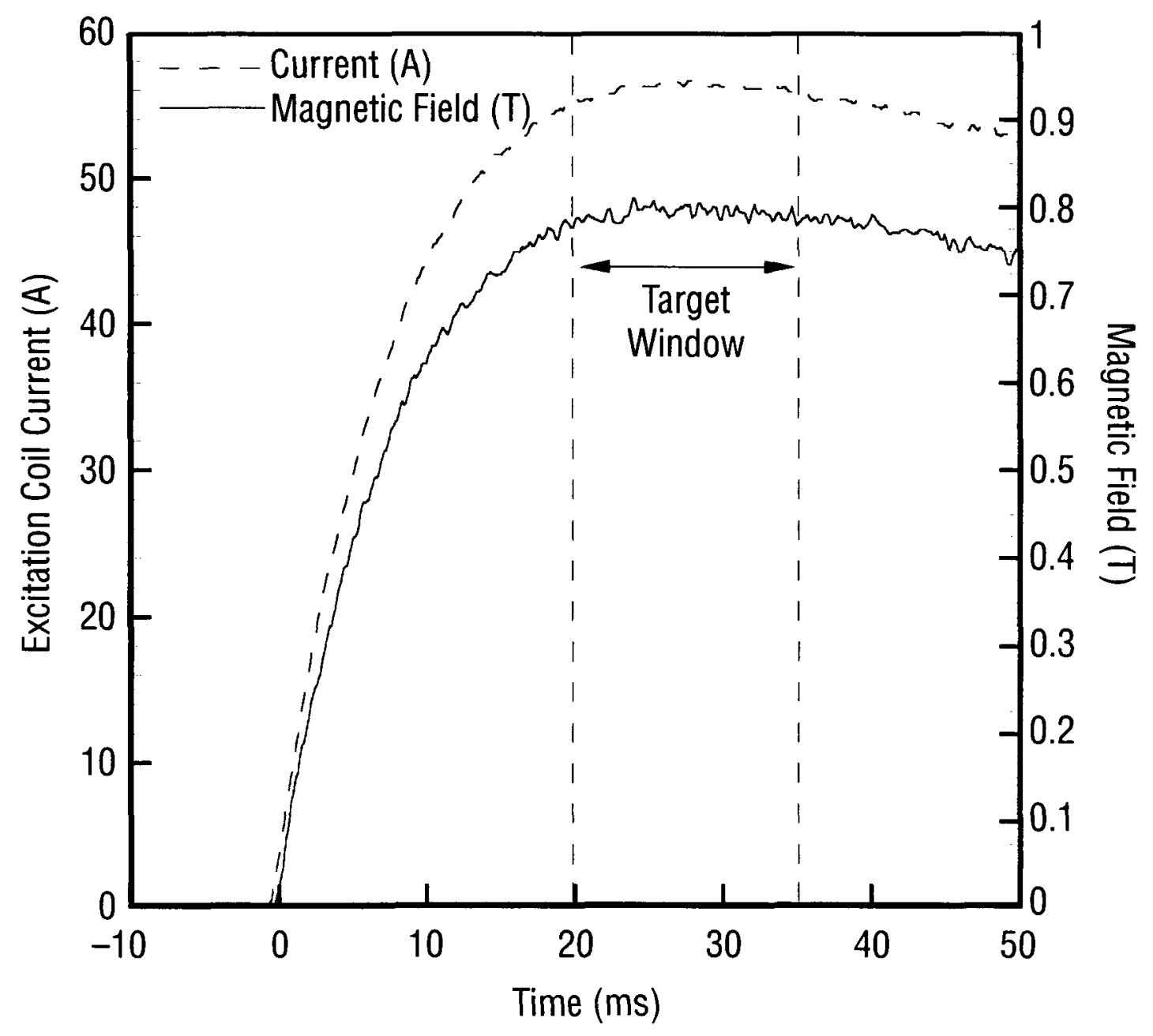

Figure 8. Measured coil current and field intensity waveforms. 


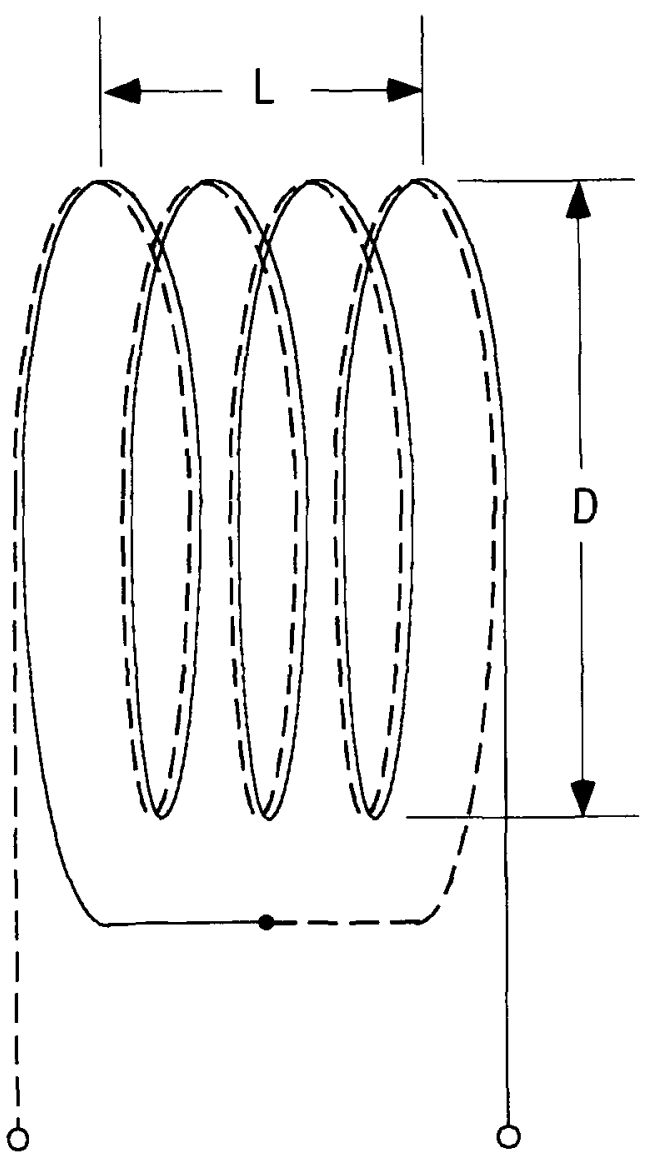

Standard Configuration

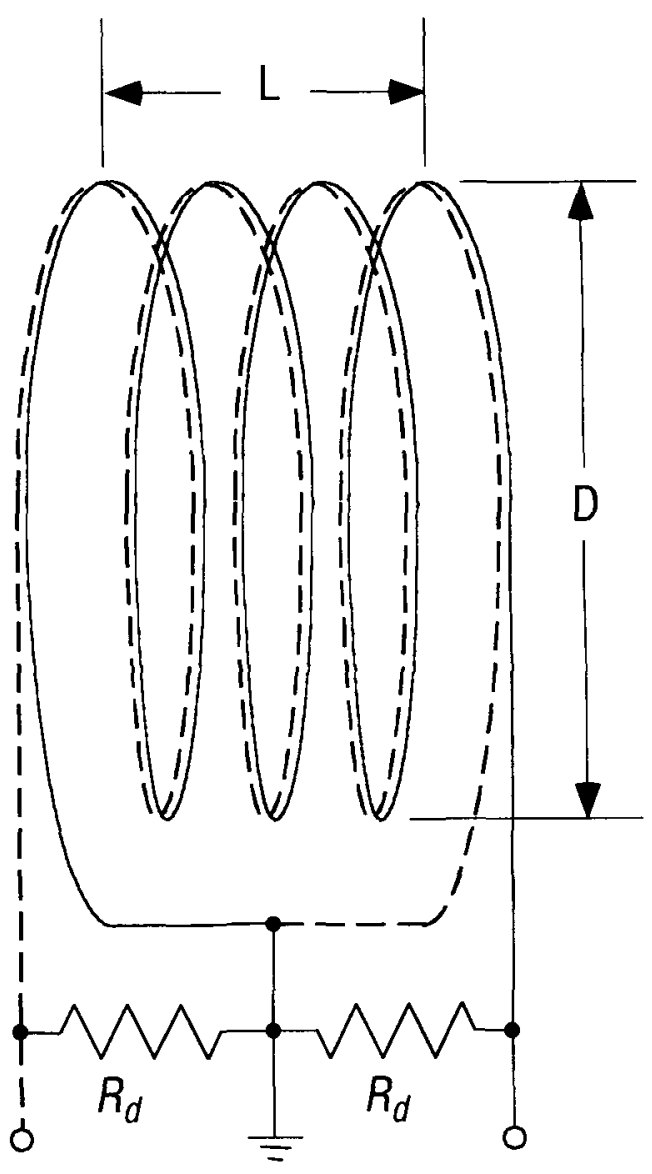

Push-Pull Configuration

Figure 9. Illustration of standard and push-pull search coil configurations. The critical damping resistance is $R_{d}=1 \mathrm{k} \Omega-\mathrm{m}$. 


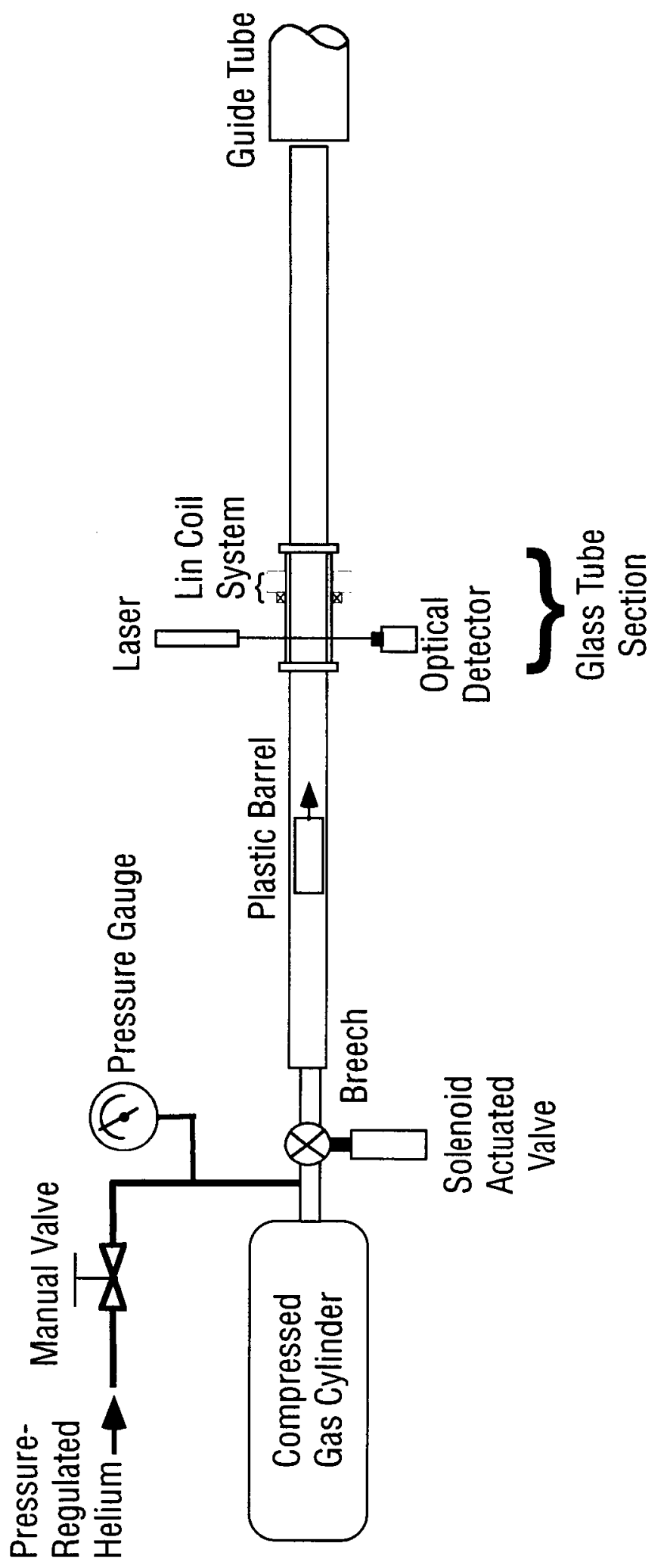

Figure 10. Schematic of experimental apparatus used for probe calibration. A light-gas gun was used to fire a $10-\mathrm{cm}$-diameter aluminum slug through the probe where velocity was inferred from the deflection of a laser beam. 


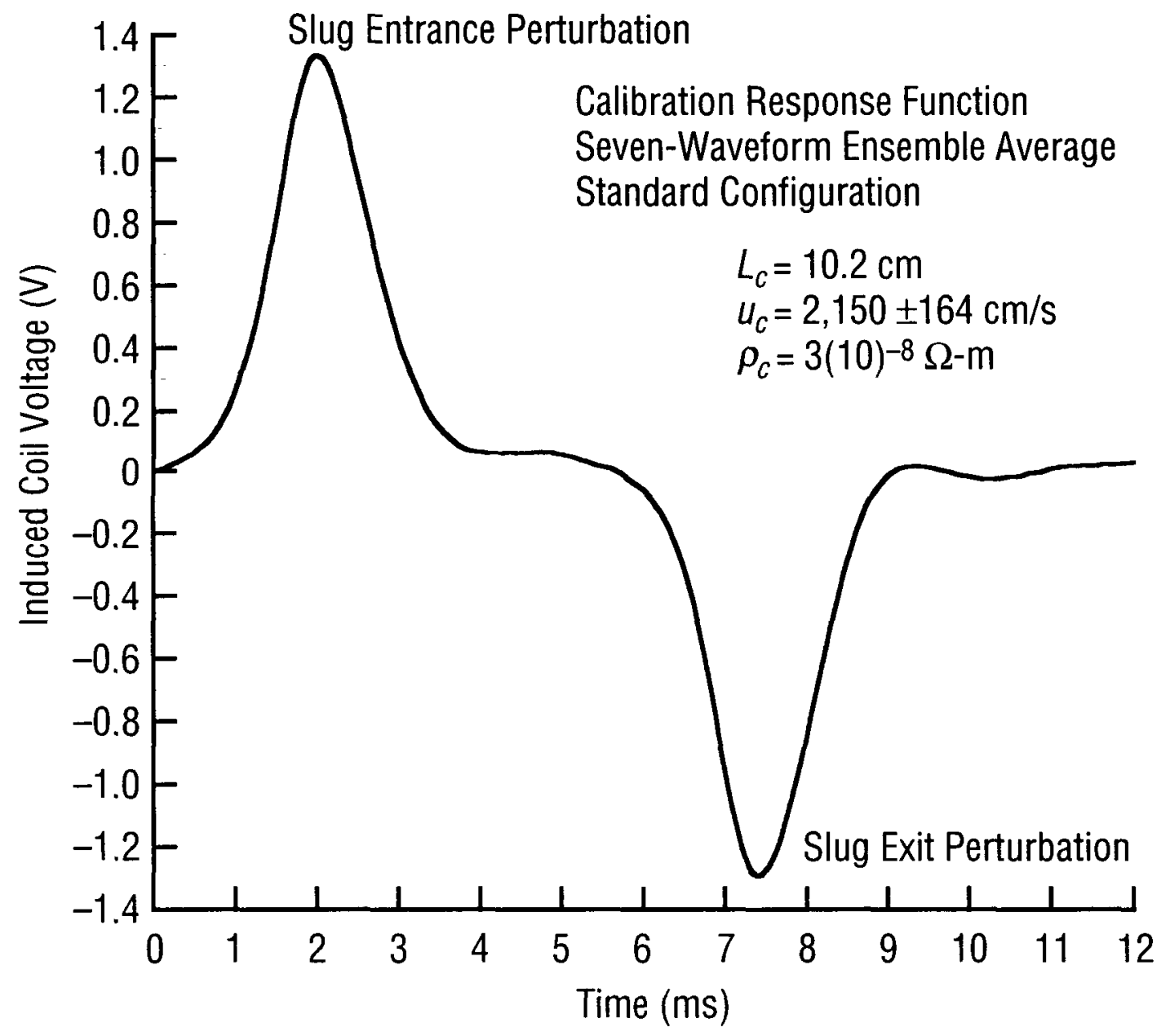

Figure 11. Measured response function for standard search coil configuration. 


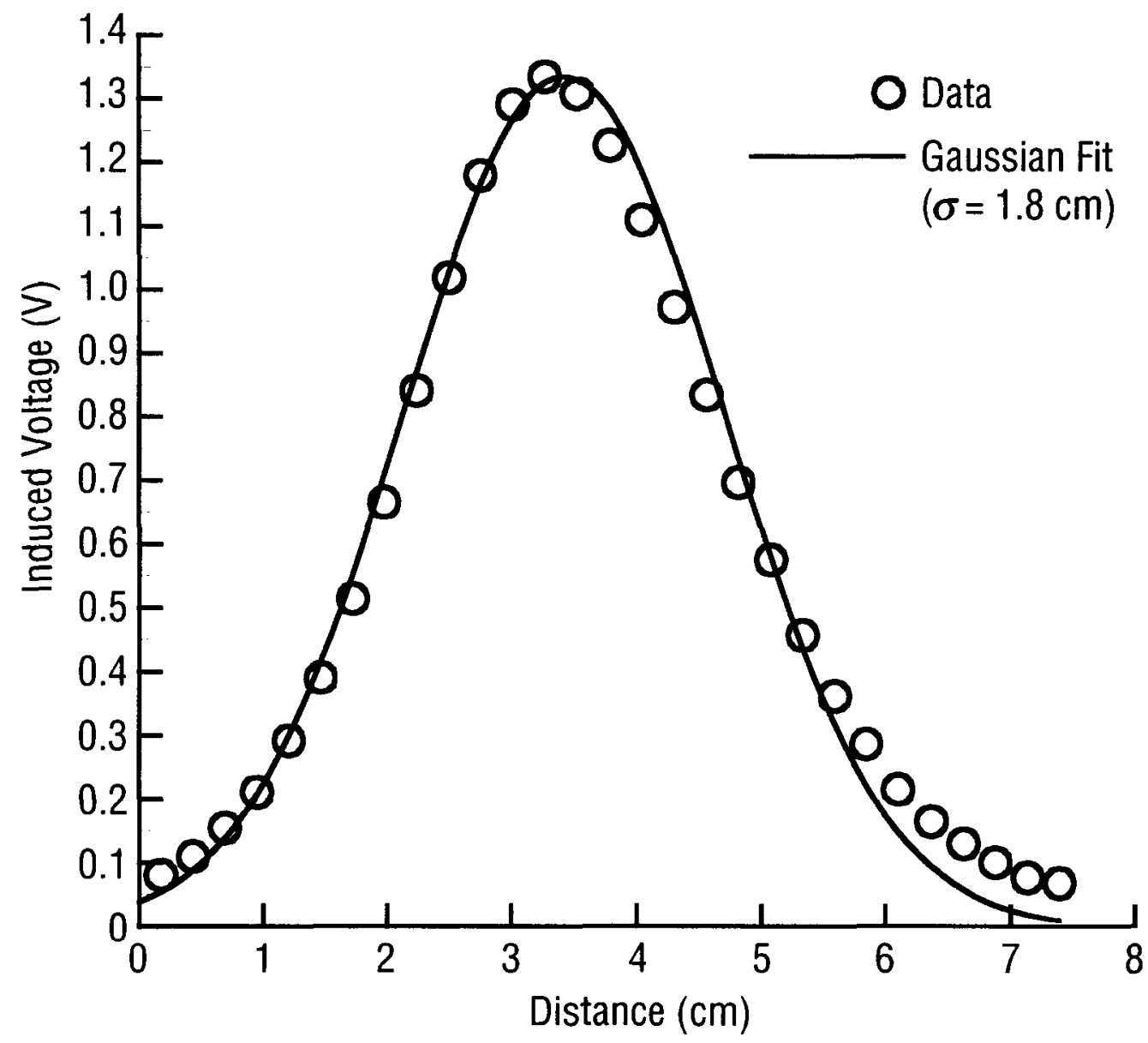

Figure 12. Gaussian fit of response function for standard search coil configuration. 


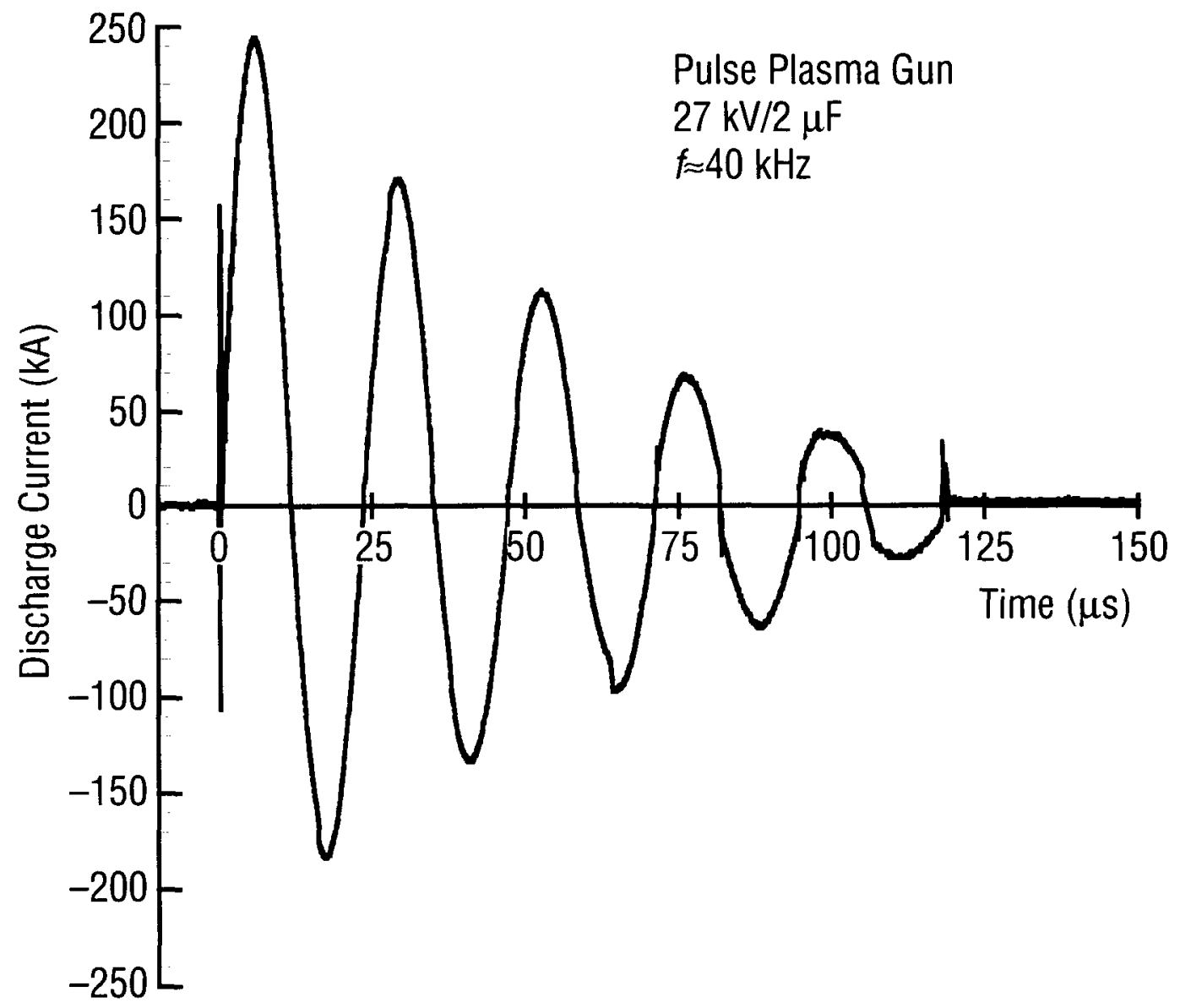

Figure 13. Measured discharge current waveform for the pulse plasma gun circuit at $27 \mathrm{kV}$. 


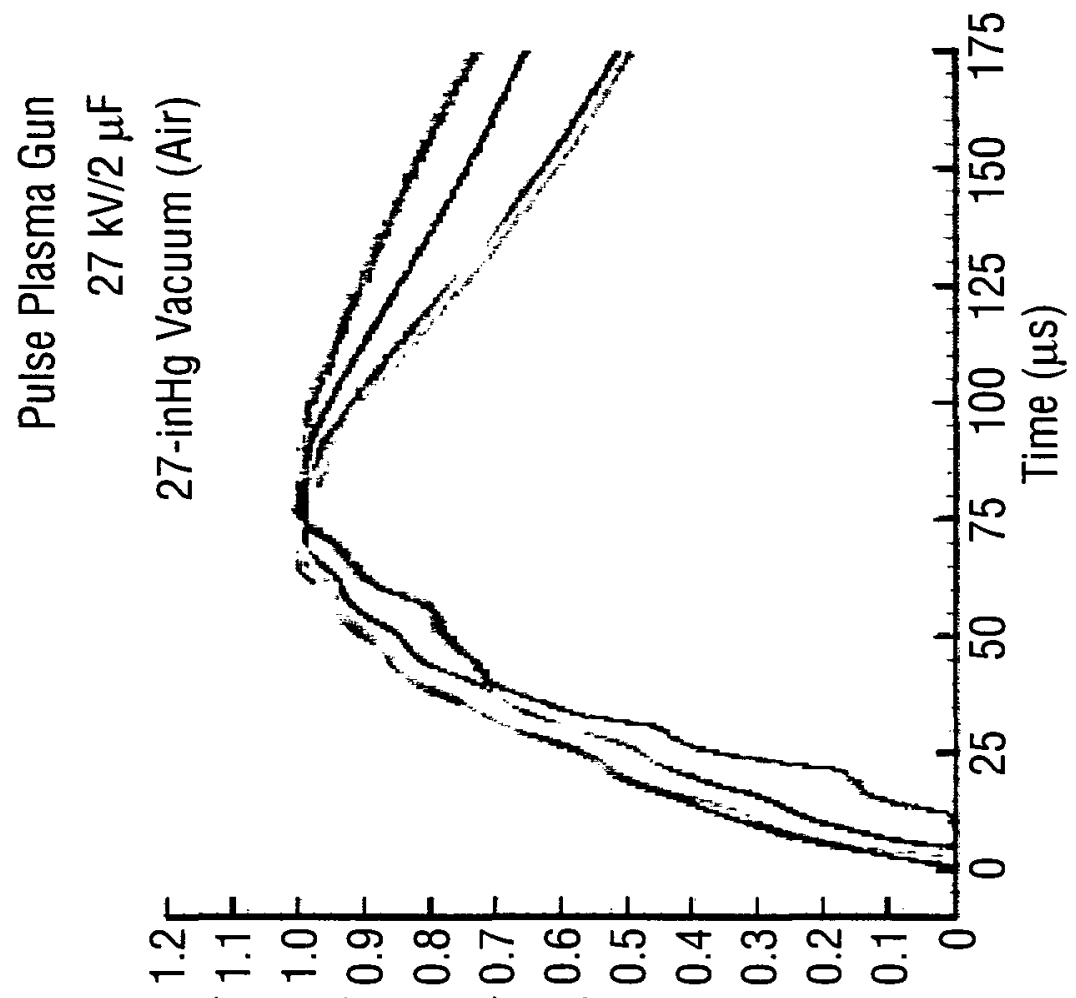

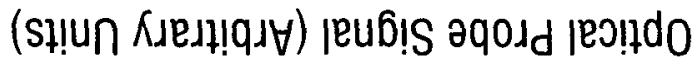

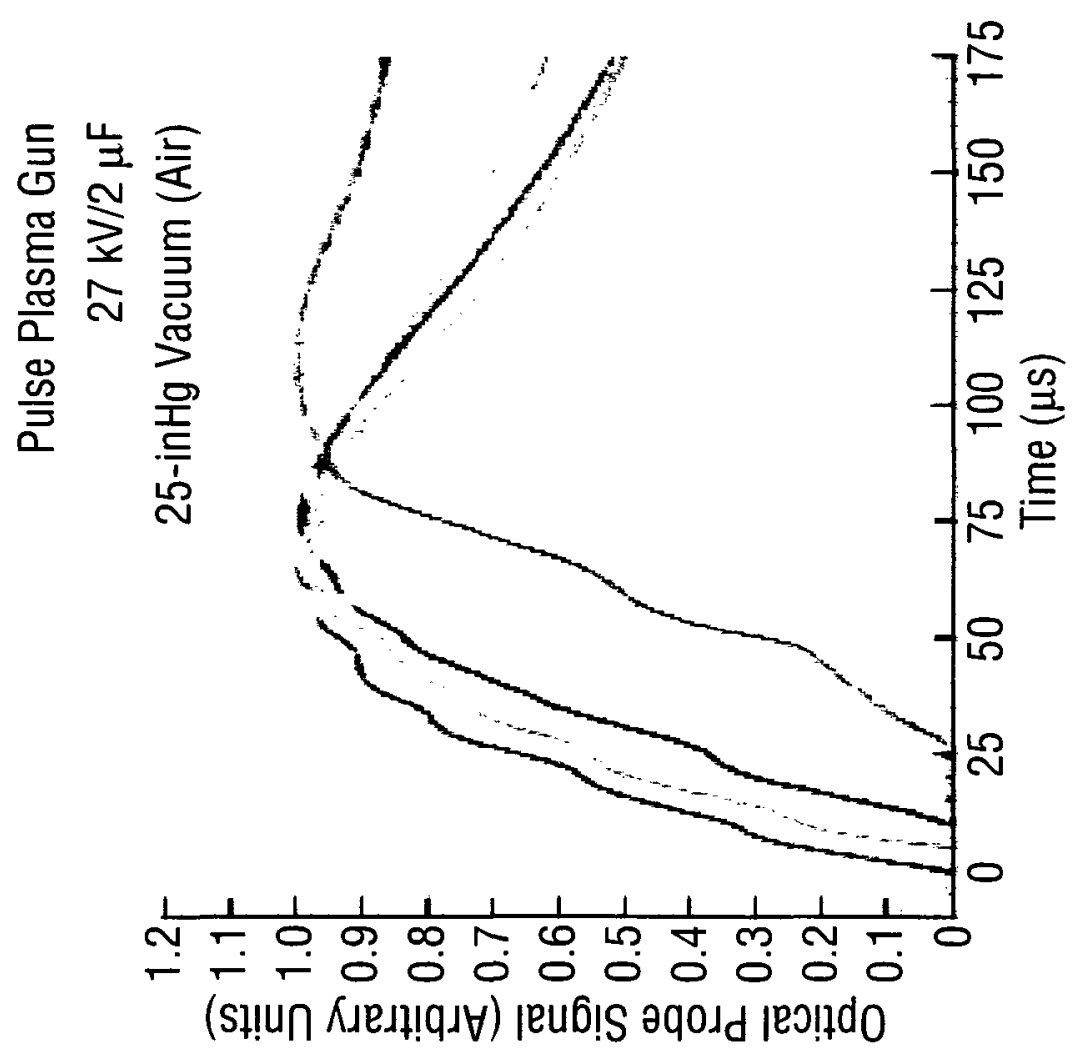

Figure 14. Ensemble-averaged optical probe waveforms at 25 - and 27 -inHg vacuum. Probes are located at $0,1,2,3,4$, and $5 \mathrm{~cm}$ from gun exit. 


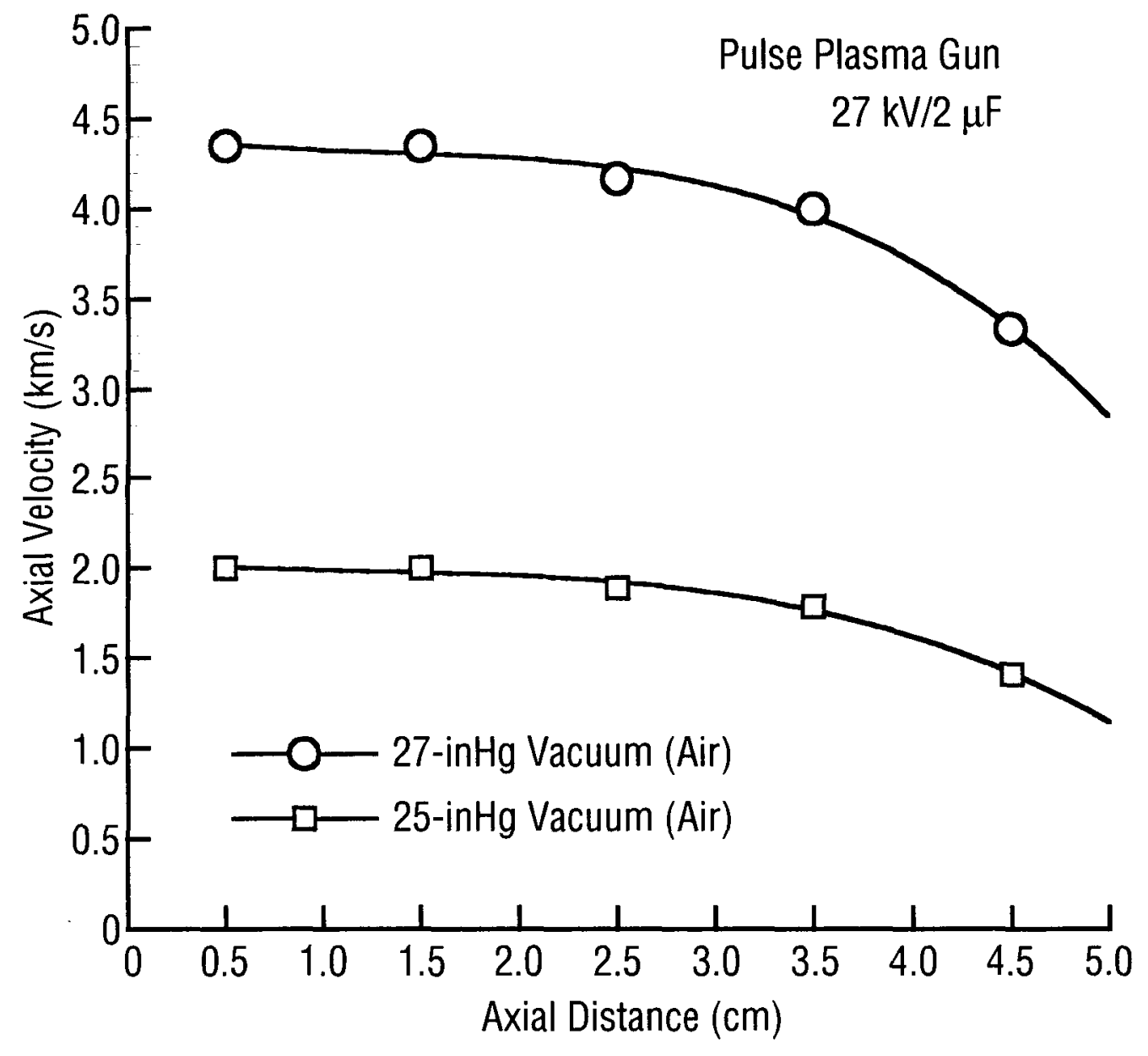

Figure 15. Plasma jet axial velocity distribution at $25-$ and $27-$ in Hg vacuum. 


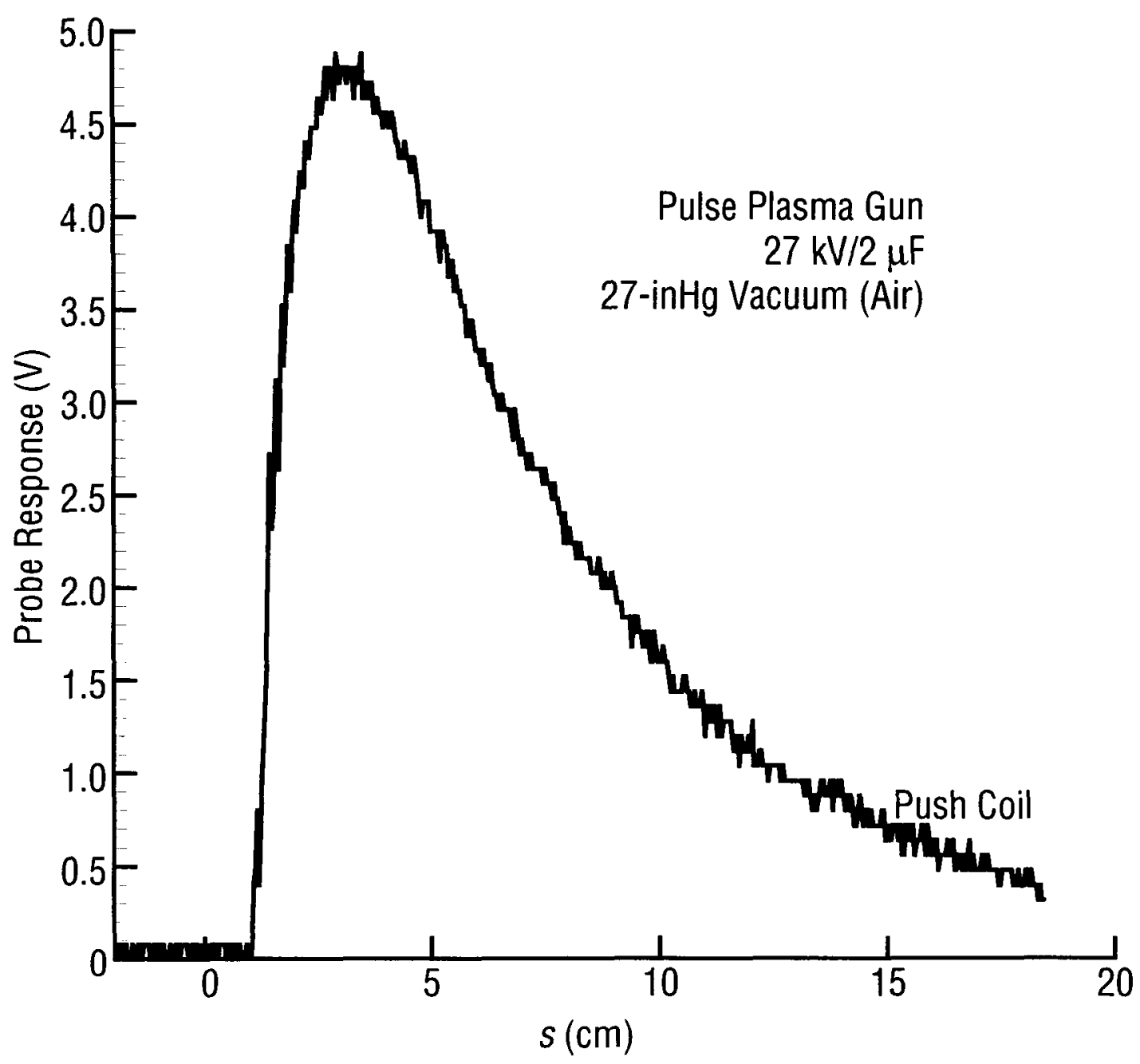

Figure 16. Measured probe response at 27 -inHg vacuum and a discharge voltage of $27 \mathrm{kV}$. 


\begin{tabular}{|c|c|c|c|c|}
\hline \multicolumn{3}{|c|}{ REPORT DOCUMENTATION PAGE } & & $\begin{array}{l}\text { Form Approved } \\
\text { OMB No. 0704-0188 }\end{array}$ \\
\hline \multicolumn{5}{|c|}{ 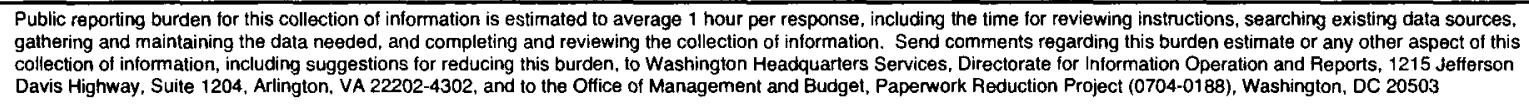 } \\
\hline 1. AGENCY USE ONLY (Leave Blank) & \multicolumn{2}{|c|}{$\begin{array}{l}\text { 2. REPORT DATE } \\
\text { March } 2003\end{array}$} & \multicolumn{2}{|c|}{$\begin{array}{l}\text { 3. REPORT TYPE AND DATES COVERED } \\
\text { Technical Publication }\end{array}$} \\
\hline \multicolumn{3}{|c|}{$\begin{array}{l}\text { 4. TITLE AND SUBTITLE } \\
\text { Magnetic Flux Compression Experiments Using Plasma Armature }\end{array}$} & \multicolumn{2}{|c|}{ 5. FUNDING NUMBERS } \\
\hline \multicolumn{5}{|l|}{$\begin{array}{l}\text { 6. AUTHORS } \\
\text { M.W. Turner,* C.W. I }\end{array}$} \\
\hline \multicolumn{3}{|c|}{$\begin{array}{l}\text { 7. PERFORMING ORGANIZATION NAMES(S) AND ADDRESS(ES) } \\
\text { George C. Marshall Space Flight Center } \\
\text { Marshall Space Flight Center, AL } 35812\end{array}$} & \multicolumn{2}{|c|}{$\begin{array}{l}\text { 8. PERFORMING ORGANIZATION } \\
\text { REPORT NUMBER } \\
\text { M-1069 }\end{array}$} \\
\hline \multicolumn{3}{|c|}{$\begin{array}{l}\text { 9. SPONSORING/MONITORING AGENCY NAME(S) AND ADDRESS(ES) } \\
\text { National Aeronautics and Space Administration } \\
\text { Washington, DC } 20546-0001\end{array}$} & \multicolumn{2}{|c|}{$\begin{array}{l}\text { 10. SPONSORING/MONITORING } \\
\text { AGENCY REPORT NUMBER } \\
\text { NASA/TP-2003-212341 }\end{array}$} \\
\hline \multicolumn{5}{|c|}{$\begin{array}{l}\text { 11. SUPPLEMENTARY NOTES } \\
\text { *Propulsion Research Center, The University of Alabama in Huntsville, Huntsville, AL } \\
\text { Prepared by the Advanced Space Transportation Program Office, Space Transportation Directorate }\end{array}$} \\
\hline \multicolumn{3}{|l|}{$\begin{array}{l}\text { 12a. DISTRIBUTIONAVAALABILITY S } \\
\text { Unclassified-Unlimited } \\
\text { Subject Category } 20 \\
\text { Standard Distribution }\end{array}$} & \multicolumn{2}{|c|}{ 12b. DISTRIBUTION CODE } \\
\hline \multicolumn{5}{|c|}{$\begin{array}{l}\text { 13. ABSTRACT (Maximum 200 words) } \\
\text { Magnetic flux compression reaction chambers offer considerable promise for controlling the plasma flow associated } \\
\text { with various micronuclear/chemical pulse propulsion and power schemes, primarily because they avoid } \\
\text { thermalization with wall structures and permit multicycle operation modes. The major physical effects of concern are } \\
\text { the diffusion of magnetic flux into the rapidly expanding plasma cloud and the development of Rayleigh-Taylor } \\
\text { instabilities at the plasma surface, both of which can severely degrade reactor efficiency and lead to plasma-wall } \\
\text { impact. A physical parameter of critical importance to these underlying magnetohydrodynamic (MHD) processes is } \\
\text { the magnetic Reynolds number }\left(R_{m}\right) \text {, the value of which depends upon the product of plasma electrical conductivity } \\
\text { and velocity. Efficient flux compression requires } R_{m}>>1 \text {, and a thorough understanding of MHD phenomena at high } \\
\text { magnetic Reynolds numbers is essential to the reliable design and operation of practical reactors. As a means of } \\
\text { improving this understanding, a simplified laboratory experiment has been constructed in which the plasma jet } \\
\text { ejected from an ablative pulse plasma gun is used to investigate plasma armature interaction with magnetic fields. As } \\
\text { a prelude to intensive study, exploratory experiments were carried out to quantify the magnetic Reynolds number } \\
\text { characteristics of the plasma jet source. Jet velocity was deduced from time-of-flight measurements using optical } \\
\text { probes, and electrical conductivity was measured using an inductive probing technique. Using air at } 27-i n H g \\
\text { vacuum, measured velocities approached } 4.5 \mathrm{~km} / \mathrm{s} \text { and measured conductivities were in the range of } 30 \text { to } 40 \mathrm{kS} / \mathrm{m} \text {. }\end{array}$} \\
\hline \multirow{2}{*}{\multicolumn{4}{|c|}{$\begin{array}{l}\text { 14. SUBJECT TERMS } \\
\text { magnetic flux compression, magnetic Reynolds number, interchange } \\
\text { instability, plasma jet, electrical conductivity, plasmadynamics }\end{array}$}} & $\begin{array}{c}\text { 15. NUMBER OF PAGES } \\
40\end{array}$ \\
\hline & & & & 16. PAICE CODE \\
\hline $\begin{array}{l}\text { 17. SECURITY CLASSIFICATION } \\
\text { OF REPORT } \\
\text { Unclassified }\end{array}$ & $\begin{array}{l}\text { 18. SECURITY CLASSIFICATION } \\
\text { OF THIS PAGE } \\
\text { Unclassified }\end{array}$ & & ICATION & 20. LIMITATION OF ABSTRACT \\
\hline
\end{tabular}

